Published in final edited form as:

Prog Mol Biol Transl Sci. 2014 ; 123: 53-82. doi:10.1016/B978-0-12-397897-4.00011-5.

\title{
Implications of Cellular Models of Dopamine Neurons for Schizophrenia
}

\author{
Na Yu ${ }^{1}$, Kristal R Tucker ${ }^{2}$, Edwin S Levitan ${ }^{2}$, Paul D Shepard ${ }^{3}$, and Carmen C Canavier ${ }^{1}$ \\ ${ }^{1}$ Department of Cell Biology and Anatomy and the Neuroscience Center of Excellence, LSU \\ Health Sciences Center, New Orleans, Louisiana ${ }^{2}$ Department of Pharmacology and Chemical \\ Biology, University of Pittsburgh, Pittsburgh, Pennsylvania ${ }^{3}$ Department of Psychiatry and the \\ Maryland Psychiatry Research Center, University of Maryland School of Medicine, Baltimore, \\ Maryland
}

\begin{abstract}
Midbrain dopamine neurons are pacemakers in vitro, but in vivo they fire less regularly and occasionally in bursts that can lead to a temporary cessation in firing produced by depolarization block. The therapeutic efficacy of antipsychotic drugs used to treat the positive symptoms of schizophrenia has been attributed to their ability to induce depolarization block within a subpopulation dopamine neurons. We summarize the results of experiments characterizing the physiological mechanisms underlying the ability of these neurons to enter depolarization block in vitro, and our computational simulations of those experiments. We suggest that the inactivation of voltage-dependent $\mathrm{Na}^{+}$channels, and in particular the slower component of this inactivation, is critical in controlling entry into depolarization block. In addition, an ether-a-go-related gene (ERG) $\mathrm{K}^{+}$current also appears to be involved by delaying entry into and speeding recovery from depolarization block. Since many antipsychotic drugs share the ability to block this current, ERG channels may contribute to the therapeutic effects of these drugs.
\end{abstract}

\section{Keywords}

bursting; depolarization block; antipsychotic drugs; substantia nigra; ventral tegmental area; pacemaker; ether-a-go-go-related gene (ERG) potassium current; $\mathrm{K}_{\mathrm{v}} 11$

\footnotetext{
Dopamine is a neuromodulatory transmitter released by several groups of neurons in the brain; here, we focus on those in the ventral tegmental area (VTA) and substantia nigra pars compacta (SNc) located in the midbrain. Although relatively few in number, these cells make extensive connections with other brain regions and subserve a variety of important brain functions (Girault and Greengard 2004). Dopamine neurons in the SNc or A9 project principally to the dorsal striatum, whereas those in the medially adjacent VTA or A10 innervate the ventral striatum as well as cortical and subcortical regions of the limbic system (Bloom et al., 1991). As suggested by this pattern of connectivity, midbrain dopamine neurons are necessary for normal motor function (Bernheimer et al., 1973) and a wide array of behavioral processes including reward signaling, affect, addiction and stress (Kalivas and Volkow 2005, Tanaka 2006, Schultz 1998). Clinically, VTA and SNc dopamine neurons have been implicated in both neurodegenerative and psychiatric disorders, such as
} 
Parkinson's disease and schizophrenia. The selective death of SNc dopamine neurons is a hallmark feature of Parkinson's disease (Bernheimer et al., 1973), and deranged reward signaling mediated by dopamine neurons in the VTA appears critical for the initiation of addiction and relapse (Kalivas and Volkow 2005). Most relevant for the purposes of this chapter, dopamine receptor blockers are effective therapeutics for psychosis and are often used to treat the positive symptoms of schizophrenia including hallucinations and delusions (Carlsson and Lindqvist 1963, Kapur and Remington 2001).

\section{Dopamine Neuron Electrophysiology}

In vivo, midbrain dopamine neurons fire irregular single spikes at 3-8 Hz (Grace and Bunney 1984a) interspersed with bursts of spikes with higher intraburst frequencies (Grace and Bunney 1984b). In freely moving rats, reward-related stimuli increase both the incidence and intensity of bursting (Hyland et al., 2002). In awake monkeys, bursts signal behaviorally relevant information about appetitive rewards (Schultz, 1998). Deprived of their afferent inputs in a slice preparation, these neurons are spontaneous pacemakers that fire single spikes between 1-4 Hz (Grace and Onn 1989). Depolarizing current steps elicit steady firing rates up to $10 \mathrm{~Hz}$, but additional depolarization causes a cessation of spiking, which is often referred to as "depolarization block" (Richards et al., 1997). Other depolarizing events in vitro can also lead to a train of high frequency action potentials followed by depolarization block, including spontaneous plateau potentials that occur when small conductance (SK) calcium-activated potassium channels are blocked (Ping and Shepard, 1996) and in response to simulated activation of an NMDA receptor conductance (Deister et al., 2009).

\section{Depolarization Block Hypothesis of Antipsychotic Drug Action}

All antipsychotic drugs currently used to treat schizophrenia block CNS dopamine receptors to varying degrees (Carlsson and Lindqvist 1963, Kapur and Remington 2001). Although receptor blockade is a rapid process, antipsychotic drugs had been reported to take up to three weeks to achieve their maximal therapeutic effects (Johnstone et al., 1978). This led to speculation that a mechanism with a longer time course than acute receptor block is required to account for the delayed therapeutic efficacy of these drugs. An important clue was provided by studies comparing the acute and chronic effects of antipsychotic drugs on the activity of dopamine neurons in anesthestized rats. Although acute administration of antipsychotic drugs increases the proportion of spontaneously active neurons, three weeks of repeated treatment with these drugs has the opposite effect, decreasing the number of spontaneously firing dopamine cells. Several lines of evidence point to the involvement of depolarization block in this phenomenon (Grace and Bunney, 1986). For example, although local application of glutamate fails to restore normal levels of population activity, compounds with inhibitory effects including dopamine (Pucak and Grace 1996) and GABA agonists are effective in increasing the number of spontaneously firing neurons. Intracellular recordings obtained from dopamine neurons in rats chronically-treated with antipsychotic drugs are consistent with these results and are characterized by small amplitude spikes and large depolarizing shifts in membrane potential indicative of depolarization-induced inactivation of spike generation (Fig. 1). Notably, the therapeutic efficacy of antipsychotic 
drugs is correlated with their ability to induce selective depolarization block in the VTA, whereas the ability to produce extrapyramidal motor side effects is correlated with their ability to induce depolarization block in the SNc (Chiodo and Bunney 1983; White and Wang 1983). Therefore, the depolarization block hypothesis of antipsychotic drug action (Grace et al., 1997) posits that the induction of depolarization block mediates the therapeutic effects of antipsychotic drugs so that the time course of induction of depolarization block determines the time course of the therapeutic effects.

The mechanism(s) responsible for the induction of depolarization block in dopamine neurons are incompletely understood but appear to involve long-loop homeostatic mechanisms. These mechanisms are hypothesized to require several weeks to fully develop, and to compensate for a decrease in dopaminergic activation of downstream targets by increasing the net excitation of the dopaminergic population. Lesions of the striatum and the nucleus accumbens, areas which form reciprocal connections with the SNc and VTA respectively, prevent the development of depolarization block in the SNc and VTA respectively (Bunney and Grace 1978, White and Wang 1983b). This effect of striatal input is likely mediated by inhibition of local inhibitory neurons, which increases the net level of excitation of the SNc and VTA dopaminergic neurons via disinhibition. Another possible slow homeostatic mechanism may be to increase the level of net excitation to dopamine neurons from the cortex or subthalamic nucleus (Grace et al 1997). Ultimately the progressive increases in net excitation lead to depolarization block, which relieves the excessive activation of dopamine systems thought to be responsible for psychosis in schizophrenia, but compromises the ability of the dopaminergic system to subserve its normal signaling functions.

A challenge to the depolarization block hypothesis of antipsychotic drug action arose when it was shown that significant therapeutic benefits in patients are actually achieved within the first days of antipsychotic administration- well before the presumed onset of depolarization block (Kapur and Seeman, 2001). It is well established that response to antipsychotic drugs is profoundly different in individuals with and without schizophrenia. This led to speculation that the effects of antipsychotic drugs may be different in animal models of schizophrenia than in control animals. In a recent study, Valenti et al. (2011) assessed the effects of first and second generation antipsychotic drugs on the activity of dopamine neurons in a wellcharacterized neurodevelopmental model of schizophrenia. In these rats, which exhibit increased baseline excitation in the VTA, acute administration of antipsychotics increased the incidence of depolarization block. However, several weeks of repeated administration were required to achieve the maximal decrease in the population activity. This suggests that in idiopathic schizophrenia, depolarization block may be involved in both the acute and delayed response to antipsychotics drugs. The implied therapeutic significance of depolarization block in the treatment of schizophrenia provides strong motivation to understand the cellular and ionic mechanisms contributing to its development.

\section{Computational Model of Pacemaking and Depolarization Block}

In order to study mechanisms of depolarization block in dopamine neurons, we developed a computational model (Kuznetsova et al., 2010) of a spiking pacemaker that enters

Prog Mol Biol Transl Sci. Author manuscript; available in PMC 2015 March 06. 
depolarization block before achieving firing rates much faster than $10 \mathrm{~Hz}$. Our model (Figure 2) is based on data obtained from the SNc subpopulation of dopamine neurons. There may be important differences in the intrinsic properties of subpopulations of dopamine neurons, but it is clear that both SNc and VTA dopamine neurons share a propensity to exhibit depolarization block. The model consists of a fast spiking sodium current $\mathrm{I}_{\mathrm{Na}}$, a delayed rectifier $\mathrm{I}_{\mathrm{K}, \mathrm{DR}}$, a transient outward potassium current $\mathrm{I}_{\mathrm{K}, \mathrm{A}}$, an SK calcium activated potassium channel $\mathrm{I}_{\mathrm{K}, \mathrm{SK}}$, an L-type calcium current $\mathrm{I}_{\mathrm{Ca}, \mathrm{L}}$, a leak current $\mathrm{I}_{\mathrm{L}}$ and an applied external stimulus current $\mathrm{I}_{\text {STIM }}$ (Figure 2A). The model has three spatial compartments representing the soma, proximal and distal dendrites (Figure 2B), and a material balance on calcium is performed in each compartment. A material balance is also performed on sodium, and an electrogenic sodium pump current, $\mathrm{I}_{\mathrm{NaP}}$, contributes a nearly constant hyperpolarizing current to the model.

Dopamine neurons exhibit an oscillation in intracellular calcium concentration during spontaneous repetitive firing of action potentials (Wilson and Calloway 2000), but in our model, this oscillation in calcium is driven by the repetitive spiking rather than the other way around as suggested in some previous models (Kuznetsov et al., 2006). Dopamine neurons have no stable resting potential, but gradually depolarize in between action potentials. During pacemaking, the following sequence of events repeats itself (Figure 3). Ltype $\mathrm{Ca}^{2+}$ channels in midbrain dopamine neurons are active at relatively hyperpolarized potentials (Durante et al., 2004), and as the model depolarizes, calcium entry via this channel increases the free $\mathrm{Ca}^{2+}$ concentration in the cytosol. When an action potential is triggered, the potassium currents are activated. They repolarize the action potential, then cause a prolonged after hyperpolarizing potential that turns off the L-type calcium channel current (blue trace in Figure 3C). Since the SK potassium channel responsible for the prolonged after hyperpolarization is voltage-independent, the time course of this portion of the cycle (Figure 3A) is dependent on the time course of the removal of $\mathrm{Ca}^{2+}$. In our model, the SK current is primarily activated in the dendrites due to their larger surface area to volume ratio, which causes larger excursion in free cytosolic $\mathrm{Ca}^{2+}$ concentration in the smaller diameter dendrites. The effect of this current in the soma therefore manifests itself only indirectly as the axial flow of current between the soma and proximal dendrites ( $\mathrm{I}_{\mathrm{SP}}$, red trace in Figure 3C). In addition to closing the L-type $\mathrm{Ca}^{2+}$ channels, the after hyperpolarization removes sodium channel inactivation so that there is sufficient sodium channel availability for the next slow depolarization to trigger an action potential. During the hyperpolarization following the action potential, calcium concentration decreases due to the very low level of activation of $\mathrm{I}_{\mathrm{Ca}, \mathrm{L}}$, turning off the SK channel current.

During the $\mathrm{Ca}^{2+}$ independent portion of the interspike interval (Figure 3B), the membrane potential changes very slowly as the L-type calcium channel opens. Activation of the L-type channel is not slow, but the net current is small (Puopolo and Bean 2007) during the interspike interval. This current (blue trace in Figure 3C) turns on gradually with increasing depolarization. In fact, in the model, the membrane potential changes so slowly over the "voltage dependent" phase of the interspike interval that L-type $\mathrm{Ca}^{2+}$ channel activation remains near its steady state value as a function of membrane potential. The slow depolarization continues as the L-type $\mathrm{Ca}^{2+}$ channels open again, and the cycle repeats. 
If a depolarizing current step of sufficient magnitude is applied to the model soma (Figure 4), depolarization block ensues. During spontaneous pacemaking, sufficient inactivation of the sodium channel is removed during the after hyperpolarizing phase of each action potential so that there is sufficient sodium channel availability to trigger the next full height action potential. In the presence of a sufficiently strong depolarizing current pulse (Figure 4A), there is insufficient after hyperpolarization following the action potentials to remove sodium channel inactivation (Figure 4B) resulting in depolarization (DP) block.

\section{Availability of Sodium Current Controls Entry into DP Block}

Kuznetsova et al., (2010) predicted that increasing the availability of sodium channels by increasing the sodium channel conductance density would delay entry into depolarization block by allowing spiking to continue at values of injected current that caused entry into depolarization block under control conditions. Figure 5 shows that for the control value of the sodium channel conductance density, the model produces sustained spiking at up to 10 $\mathrm{Hz}$ at $400 \mathrm{pA}$ of depolarizing current injected at the soma; if the level of injected current is increased, the neuron ceases to spike, indicated by the end of the red curve at those values. Increasing the sodium channel conductance density allows sustained spiking at faster frequencies and higher levels of depolarizing current than was possible with the control value.

In order to test this prediction in dopamine neurons, we used the dynamic clamp, which allows the time course of virtual conductances to be calculated in real time based on the time course of the measured value of the somatic membrane potential. A virtual conductance is realized by injecting the current produced by the product of the instantaneous value of the conductance and the driving force into the soma. This technique enabled Tucker et al. (2012) to show that augmenting the sodium conductance indeed allowed dopamine neurons to continue spiking in the presence of a level of depolarizing current that caused entry into depolarization block under control conditions (Figure 6). Current pulses that supported continuous spiking under control conditions led to depolarization block in the presence of submaximal concentrations of the sodium channel blocker, TTX. These effects were reversed by re-introducing a sodium conductance via dynamic clamp (Tucker et al., 2012). Understanding the precise mechanism of depolarization block in dopamine neurons may lead to improved therapeutics.

\section{The Ether-a-Go-Go-Related Gene Potassium Channel and Schizophrenia}

Although all antipsychotic drugs act as dopamine receptor blockers, many share another common effect, namely, blockade of ether-a-go-go-related gene (ERG) Kv11.1 potassium channels (Table 1)(Shepard et al., 2007). The first evidence that midbrain dopamine neurons might express these channels was provided by a study showing a slow, calcium-independent component of an after hyperpolarization that was partially blocked by the antipsychotic drug haloperidol (Nedergaard 2004). The main effect of ERG blockade in that study was a reduction in the duration of a pause in spontaneous firing that occurs following trains of spikes elicited by a square pulse of depolarizing current. This post-stimulus pause in firing may be analogous to the characteristic pause in spontaneous activity that follows a burst of 
spikes (Shepard and Bunney, 1991). Blocking the ERG current with the sulfonanilide antiarrhythmic drug E-4031 prolonged episodes of depolarization block in dopamine neurons in vitro (Canavier et al., 2007). Ji et al., (2012) provided evidence that both E-4031 and another selective ERG channel blocker, the peptide toxin, $\mathrm{rBeKm}-1$, had similar effects on dopamine neurons activity. As it is extremely unlikely that these structurally disparate drugs would have a second common site of action, it was concluded that the effects of both compounds are mediated by ERG channel blockade.

Activation of the ERG current with prolonged depolarization may contribute to delaying depolarization block by simply making the net current less depolarizing. However, the ERG current is also uniquely suited to remove sodium channel inactivation after a spike because of its kinetic scheme, which is shown in Figure 7. This channel activates slowly with depolarization, but inactivates rapidly. Furthermore, once inactivated, the ERG channel must pass through an open state before closing. During depolarization, channels accumulate in the inactivated state. However, upon hyperpolarization they accumulate in the open state due to the bottleneck caused by slow deactivation, causing a "resurgent" current after an action potential. This resurgent current can contribute to the after hyperpolarization required to remove sodium channel inactivation and potentially delay entry into depolarization block.

\section{ERG Conductance Both Delays Entry Into and Speeds Recovery From Depolarization Block}

In order to determine what effect ERG channel blockade might have on depolarization block, Ji et al., (2012) induced depolarization block in a slice preparation in two ways. First, the dynamic clamp was utilized to inject a square pulse of virtual NMDA conductance that increased the spike frequency but led to depolarization block at the end of the train of spikes. Secondly, application of a negative modulator of the SK current led to a spontaneous depolarization that manifested as a high frequency train of spikes followed by depolarization block. These protocols were used to mimic in an in vitro preparation the natural bursting that occurs in vivo (Figure 1).

Figure 8A shows a control trace from a spontaneously pacemaking dopamine neuron in a slice preparation and the effect of applying a square pulse of virtual NMDA conductance, (black bar above the membrane potential trace). This virtual excitatory conductance activates instantaneously with depolarization and has a synaptic reversal of potential of 0 $\mathrm{mV}$. The resultant injected current at first increases the spike rate, then leads to depolarization block. After ERG block by E-4031 (Figure 8B), spiking is maintained for a much shorter duration and far fewer spikes are evoked. These results support our proposition that, under control conditions, the ERG current delays entry into depolarization block.

As described in the computational modeling section above, the SK channel current plays a critical role in regular pacemaking. In the model, the prolonged after hyperpolarization produced by the SK channel closes the L-type $\mathrm{Ca}^{2+}$ channels, ensuring that each slow depolarization leads to only a single spike. If the SK channel is blocked by apamin (Ping and Shepard 1996; Johnson and Wu 2004) or if its affinity for calcium is decreased by the negative modulator NS-8593, a runaway depolarization unopposed by the SK channel can 
occur, resulting in a depolarized plateau (Figure 9A). If, under these conditions, the ERG channels are blocked by E-4031, the duration of the plateau is markedly lengthened (Figure 9B and C). We conclude that under control conditions, the ERG current contributes to spontaneous repolarization of the plateau. We suspect that this repolarization occurs via regenerative deactivation of the L-type $\mathrm{Ca}^{2+}$ channel that supports the plateau (Ping and Shepard, 1996; Nedergaard et al., 1993). In some neurons, ERG channel blockade caused dopamine neurons to remain depolarized indefinitely (Figure 9D). In these neurons, hyperpolarizing pulses could briefly re-establish spiking prior to re-entry into depolarization block.

These results show that blockade of the ERG current affects the propensity of dopamine neurons to enter and remain in state of a depolarization block. Since the therapeutic action of antipsychotics has been associated with their propensity to induce depolarization block, the possibility exists that part of this therapeutic action may be mediated by their ability to block the ERG current and thereby promote depolarization block (Shepard et al., 2007).

\section{Computational Model of Bursting and DP Block}

Our computational model of pacemaking, taken from Kuznetsova et al., 2010 and described above (Figures 3 and 4), was not sufficient to capture burst firing induced by a virtual pulse of NMDA, the spontaneous plateaus induced by negative modulation of the SK current, or repolarization of those plateaus. Since the model did not contain an ERG current, it was also not capable of modeling the effects of ERG block on these phenomena. The computational model presented in Ji et al., 2012 (Figure 10) made the following major modifications to the model of Kuznetsova et al., (2010): the addition of the slow ERG current ( $\left.\mathrm{I}_{\mathrm{K}, \mathrm{ERG}}\right)$ and the addition of a second, slower component of sodium channel inactivation. The ERG current was modeled using the kinetic scheme shown in Figure 7, fit to the data presented in Figure $1 \mathrm{AB}$ of Ficker et al., 1998. The three-compartment schematic structure of the model was preserved (Figure 10B). Here, we explain why these modifications were necessary and present an improved parameter set (see Appendix for details) for the modified model that better captures the effects observed in brain slices. The A type potassium current and the sodium pump current were not included in the model for bursting. However, the nonspecific hyperpolarization-activated cation current $\left(\mathrm{I}_{\mathrm{H}}\right)$ based on the description of Migliore et al., 2008 and an $\mathrm{M}$ type $\mathrm{K}^{+}$current based on the description of Drion et al., 2010 were included. These modifications were not critical for either pacing or bursting activity.

For the passive properties of the model, the axial resistivity was set to $40 \Omega \mathrm{cm}$ and the capacitance to $1 \mu \mathrm{F} / \mathrm{cm}^{2}$. First, the model was silenced by simulated injection of sufficient hyperpolarizing current into the soma in order to hold the model neuron at $-65 \mathrm{mV}$. Then the time constant and input resistance were measured using small amplitude (40 pA) hyperpolarizing pulses. The membrane time constant of the model was $31 \mathrm{msec}$ compared to reported values of 30-40 ms in dopamine neurons (Johnson and North, 1992) and the input resistance was $476 \mathrm{M} \Omega$ under control conditions, within the reported range of 100-500 M $\Omega$ (Ji et al., 2012, Johnson and North, 1992, Grace and Onn, 1989). ERG block, simulated by setting the conductance for $\mathrm{I}_{\text {ERG }}$ to zero, resulted in a $502 \mathrm{M} \Omega$ input resistance. These results were similar to those observed in brain slices following ERG block (Ji et al., 2012).

Prog Mol Biol Transl Sci. Author manuscript; available in PMC 2015 March 06. 
In order to simulate the experimental results presented in Figures 6, 8 and 9, it was necessary to incorporate a second, slow component of sodium channel inactivation that was recently described in midbrain dopamine neurons (Ding et al., 2011). Figure 11A1 shows the voltage dependence of the two sodium inactivation variables ( $h$ and $h s$ ) in the model. The description of the Hodgkin-Huxley type inactivation variable $h$ was based on experimental data from nucleated patches (Seutin and Engel, 2010). The time course of $h s$ is slower than that of $h$, and its steady state voltage dependence has not been characterized in dopamine neurons. Two components of inactivation are evident during recovery from inactivation, but entry into the slow inactivation state cannot be observed during a single pulse protocol because it is obscured by entry into the fast inactivated state. However, during multiple pulses that are spaced sufficiently close together, there is incomplete recovery from the slowly inactivating state, so that the sodium current evoked by multiple pulses declines as the train progresses. This protocol was applied in the model (Figure 11A2) using $3 \mathrm{~ms}$ voltage clamp steps separated by $100 \mathrm{~ms}$, and fitted to the data of Ding et al., 2011.

In order to simulate the experimental rescue from depolarization block by additional sodium conductance (Figure 6), the model neuron was held hyperpolarized at $-65 \mathrm{mV}$ and a two second current depolarizing step was applied to drive the model cell into depolarization block (Figure 11B1). An additional amount of sodium conductance was injected into the soma only, in order to prevent depolarization block (Figure 11B2). For consistency with the dynamic clamp protocol used in Tucker et al., 2012, the injected virtual conductance did not have the $h s$ component modeled in this simulated sodium conductance. The half inactivation voltage for $h s$ is $-51 \mathrm{mV}$, indicated by the horizontal dashed lines in Figure 11B1 and 11B2. Spiking cannot be sustained if the membrane potential does not drop below this value, because inadequate slow inactivation is removed during the interspike interval. The removal of inactivation between spikes (see Figure 11B3) allows spiking to continue with $300 \mathrm{nS}$ of virtual sodium conductance added in Figure 11B2, whereas it dies out under control conditions in Figure 11B1. Figure 11B4 shows that fast inactivation continues to be removed after each spike with $300 \mathrm{nS}$ virtual sodium conductance added (Figure 11B2), but approaches a steady state under control conditions (Figure 11B1). The key difference is the amount of available sodium conductance prior to each spike (the fraction of non-inactivated sodium conductance), indicated by the peaks in Figure 11B5. These simulations suggest that failure to recover from slow inactivation drives the model neuron into depolarization block, and rescue from depolarization block occurs because the added conductance results in larger availability of sodium channels that can contribute to the regenerative activation required for spike generation.

In order to model the experimental results showing that blocking the ERG current speeds entry into depolarization block in the presence of an applied pulse of virtual NMDA conductance (Figure 8), a square pulse of NMDA conductance was applied in the soma to the model in the free running pacemaker condition (Figure 12A) both under control conditions (top) and with the ERG conductance set to zero to simulate blockade of this current (bottom). NMDA greatly increased the frequency of spiking and ultimately led to depolarization block. An NMDA conductance pulse increases the frequency to a higher level 
than can be achieved with a current pulse because the regenerative voltage dependence of the NMDA conductance can compensate for decreased sodium channel availability. The simulated ERG block increased the frequency of pacemaking by approximately $100 \%$, somewhat more than the mean percent increase observed experimentally (Ji et al., 2012). ERG block also decreased the number of spikes in the NMDA evoked burst as well as the duration of the burst. The gradual accumulation of inactivation, shown in Figure $12 \mathrm{~B}$ as a decrease in the non-inactivated fraction, is responsible for entry into depolarization block (cf. Figure 11). ERG block (dashed trace) accelerates this decrease compared to control (solid trace), resulting in faster entry into depolarization block. The contribution from the faster component of inactivation is not immediately clear from Figure 12B, so Figure 12C shows an expanded view of a single action potential under each condition at a similar time point. The membrane potential during the interspike interval is more depolarized with the ERG block (dashed line) compared to control (solid line), explaining the faster decrease in non-inactivated channels since the time constant for slow inactivation is faster at more depolarized potentials. In addition, there is less removal of fast inactivation after a spike with ERG block than under control conditions. Thus, fewer spikes are elicited in an NMDAevoked burst when the ERG current is blocked compared to control. Due to the kinetic scheme that characterizes the ERG current (Figure 7), the open fraction of ERG channels decreases during the rising phase of the action potential and exhibits a small increase during the after hyperpolarization (Figure 12C). This results in more removal of sodium channel inactivation, which in turn leads to a larger spike height, a greater number of spikes, and a longer duration of bursting spikes when NMDA is applied for the control case compared to the ERG block condition.

To model the experimental results showing that blocking the ERG current delays or prevents recovery from depolarization block during plateaus induced by block (or negative modulation) of the SK current (Figure 9), the SK channel conductance in the model was set to zero. This disrupted pacemaking activity and produced bursts of action potentials terminating in depolarization block and a depolarized plateau (Figure 13A1). This plateau repolarized spontaneously and abruptly as in the experimental data (compare to Figure 9A). The plateau resulted from the failure of the action potentials to turn off the L-type calcium current shown in Figure 13B1 (compare to the calcium-dependent phase in the pacemaking model in Figure $3 \mathrm{~A}$ and $\mathrm{C}$ in which the L-type $\mathrm{Ca}^{2+}$ current essentially turns off during the AHP following an action potential). The $\mathrm{Ca}^{2+}$-activated $\mathrm{SK}$ potassium current is largely responsible for this portion of the AHP, and in its absence, bursts of spikes can replace pacemaking in which a single spike rides each depolarizing wave. The excessive unopposed depolarization produced by the regenerative, autocatalytic L-type $\mathrm{Ca}^{2+}$ current results in depolarization block, which is sustained until the slowly activating ERG current (Figure $13 \mathrm{C} 1$ ) accumulates sufficiently during the depolarization to change the total net current from inward to outward at the arrow in panels B1,C1 and D1. The actual slow variable is not the fraction of activated channels, but rather the sum of the open and inactivated channels due to the bottleneck, or slow transitions between the open and closed states compared to the fast transitions between the open and inactivated states. The hyperpolarization that terminates the plateau is sudden for two reasons. First, the L-type channels close regeneratively, in that hyperpolarization closes channels and reduces the inward current, which adds to the 
hyperpolarization. Second, ERG channels that are inactivated must pass through the open state prior to closing, and the transition from inactivated to open is fast relative to the transition from open to closed, so during the hyperpolarization there is a brief increase in the number of open channels (Figure 13D1) that speeds the hyperpolarization.

In the model, a 30\% reduction of the ERG current greatly prolongs the plateau phase (Figure 13A2), whereas complete blockade completely prevents spontaneous repolarization of the plateau (Figure 13E). In the experimental data presented in Figure 9, the application of the ERG channel blocker E-4031 had variable effects. In at least some instances, the plateau did not spontaneously repolarize, as in Figure 9D. In these cases, spiking could be restored temporarily by the application of a brief hyperpolarizing current pulse. However, depolarization block re-established itself in these cases. In the model, partial block of the ERG current extends the plateau by increasing the amount of time required for the ERG current to build up to the point that the net outward current exceeds the inward current. In the example given in Figure 13A2, the ERG current illustrated in Figure 13C2 and the Ltype $\mathrm{Ca}^{2+}$ current in Figure 13B2 are in close balance and near steady state. During this period, if noise were included in the model, the duration of the plateau becomes random because a slight increase in outward current is enough to trigger the steep, regenerative repolarization of the plateau. Although the driving force for the L-type $\mathrm{Ca}^{2+}$ current is increasing during this repolarization, the current drops sharply due to the steepness of the voltage dependence in this potential range. Similarly, the fraction of open ERG channels increases during the repolarization, partially offsetting the decrease in driving force for this potassium channel. For the case of complete ERG block in the model (Figure 13E), brief hyperpolarizing pulses relieve depolarization block by turning off the L-type $\mathrm{Ca}^{2+}$ current. As this current gradually depolarizes the membrane, depolarization block is re-established. The experimentally observed variability in the effect of the ERG channel block on plateau duration, and the fact that ERG block does not cause permanent depolarization block in every case, indicates that there is heterogeneity between neurons in the contribution of the ERG conductance to repolarization of the plateau. It is likely that some other slow current contributes to plateau repolarization in addition to the ERG current, and that this current is responsible for repolarization of the plateau in the neurons that did not remain in depolarization block after the ERG block.

\section{Conclusions}

Here we have used a model dopamine neuron to explore the roles of slow inactivation of the sodium channel and of the ERG potassium channel in depolarization block. During prolonged depolarization, sodium channels accumulate in the inactivated state due to a slow component of inactivation, and by increasing the sodium conductance depolarization block can be reversed. Blocking the ERG current accelerates entry into depolarization block by promoting entry into and hindering recovery from $\mathrm{Na}^{+}$channel inactivation. Furthermore, blocking the ERG current delays or even prevents recovery from spontaneous episodes of depolarization block when the SK channel is negatively modulated. Since antipsychotic drugs block ERG as a side effect, it is conceivable that some of the therapeutic benefits of these drugs are derived by increasing the tendency of dopamine neurons to go into depolarization block.

Prog Mol Biol Transl Sci. Author manuscript; available in PMC 2015 March 06. 
If increasing the tendency for midbrain ventral tegmental dopamine neurons to enter depolarization block has therapeutic value in schizophrenia, then drugs tailored to directly increase depolarization block in these neurons may have potential to provide improved relief from positive symptoms. Possible strategies include selectively reducing the after hyperpolarization following an action potential, increasing the fraction of sodium channels expressing slow inactivation, increasing the L-type calcium channel current responsible for plateau potentials, and/or decreasing the slow potassium currents activated by depolarization. Conversely, if depolarization block in nigral dopamine neurons causes extrapyramidal side effects, then drugs that counter depolarization block in these neurons by the opposite strategies would minimize side effects. Clearly, it will be important to understand the heterogeneous aspects of intrinsic membrane properties of dopaminergic populations in the midbrain to design better therapeutics.

\section{Acknowledgement}

This work was supported by NIH grant 5R01NS061097-05 to CCC and P30-GM103340.

\section{References}

Bernheimer H, Birkmayer W, Hornykiewicz O, Jellinger K, Seitelberger F. Brain dopamine and the syndromes of Parkinson and Huntingdon: Clinical, morphological, and neurochemical correlations. J Neurosci. 1973; 20:415-455.

Bloom, FE.; Roth, RH.; Cooper, JR. The biochemical basis of neuropharmacology. Oxford: Oxford University Press; 1991.

Bunney BS, Grace AA. Acute and chronic haloperidol treatment: comparison of effects on nigral dopaminergic cell activity. Life Sci. 1978; 23:1715-1727. [PubMed: 31529]

Canavier CC, Oprisan SA, Callaway J, Ji H, Shepard PD. Computational model predicts a role for ERG current in repolarizing plateau potentials in dopamine neurons: implications for modulation of neuronal activity. J. Neurophysiol. 2007; 98:3006-3022. [PubMed: 17699694]

Carlsson A, Lindqvist M. Effect of chlorpromazine or haloperidol on formation of 3-methoxytyramine and normetanephrine in mouse brain. Acta Pharmacol. Toxicol. (Copenh). 1963; 20:140-144. [PubMed: 14060771]

Chiodo LA, Bunney BS. Typical and atypical neuroleptics: Differential effects of chronic administration on the activity of A9 and A10 midbrain dopaminergic neurons. J. Neurosci. 1983; 3(8):1607-1619. [PubMed: 6135762]

Deister CA, Teagarden MA, Wilson CJ, Paladini CA. An intrinsic neural oscillator underlies dopaminergic neuron bursting. J. Neurosci. 2009; 29:15888-15897. [PubMed: 20016105]

Ding S, Wei W, Zhou FM. Molecular and functional differences in voltage-activated sodium currents between GABA projection neurons and dopamine neurons in the substantia nigra. J. Neurophysiol. 2011; 106:3019-3034. [PubMed: 21880943]

Drion G, Bonjean M, Waroux O, Scuvee-Moreau J, Liegeois JF, Sejnowski TJ, Sepulchre R, Seutin V. M-type channels selectively control bursting in rat dopaminergic neurons. Eur. J. Neurosci. 2010; 31:827-835. [PubMed: 20180842]

Durante P, Cardenas C, Whittaker J, Kitai S, Scroggs R. Low-threshold L-type calcium channels in rat dopamine neurons. J. Neurophysiol. 2004; 91:1450-1454. [PubMed: 14645383]

Ficker E, Jarolimek W, Kiehn J, Baumann A, Brown AM. Molecular determinants of dofetilide block of HERG K+ channels. Circ. Res. 1998; 82:386-395. [PubMed: 9486667]

Johnstone EC, Crow TJ, Frith CD, Carney MW, Price JS. Mechanism of the antipsychotic effect in the treatment of acute schizophrenia. Lancet. 1978; 1:848-851. [PubMed: 76797]

Girault JA, Greengard P. The neurobiology of dopamine signaling. Arch. Neurol. 2004; 61:641-644. [PubMed: 15148138] 
Grace AA, Bunney BS. The control of firing pattern in nigral dopamine neurons: Single spike firing. J. Neurosci. 1984a; 4:2866-2876. [PubMed: 6150070]

Grace AA, Bunney BS. The control of firing pattern in nigral dopamine neurons: Burst firing. J. Neurosci. 1984b; 4:2877-2890. [PubMed: 6150071]

Grace AA, Bunney BS. Induction of depolarization block in midbrain dopamine neuron by repeated administration of haloperidol: analysis using in vivo intracellular recording. J. Pharm. Exper. Thera. 1986; 238:1092-1100.

Grace AA, Bunney BS, Moore H, Todd CL. Dopamine-cell depolarization block as a model for the therapeutic actions of antipsychotic drugs. Trends Neurosci. 1997; 20:31-37. [PubMed: 9004417]

Grace AA, Ohn S-P. Morphology and electrophysiological properties of immuno-cytochemically identified rat dopamine neurons recorded in vitro. J. Neurosci. 1989; 9:3463-3481. [PubMed: 2795134]

Hyland BI, Reynolds JNJ, Hay J, Perk CG, Miller R. Firing modes of midbrain dopamine cells in the freely moving rat. Neurosci. 2002; 114:475-492.

Ji H, Tucker K, Putzier I, Huertas MA, Levitan ES, Canavier CC, Horn J, Shepard PD. Functional characterization of ether-a-gogo-related potassium channels in midbrain dopamine neurons: Implications for a role in depolarization block. Eur. J. Neurosci. 2012; 36(7):2906-2916. [PubMed: 22780096]

Johnson SW, North RA. Two types of neurone in the rat ventral tegmental area and their synaptic inputs. J. Physiol. 1992; 450:455-468. [PubMed: 1331427]

Johnson SW, Wu YN. Multiple mechanisms underlie burst firing in rat midbrain dopamine neurons in vitro. Brain Res. 2004; 1019(1-2):293-296. [PubMed: 15306267]

Kalivas PW, Volkow ND. The neural basis of addiction: A pathology of motivation and choice. A. J. Psychiatry. 2005; 162:1403-1413.

Kapur S, Remington G. Dopamine D2 receptors and their role in atypical antipsychotic action: Still necessary and maybe even sufficient. Biol. Psychiatry. 2001; 50:873-883. [PubMed: 11743942]

Kapur S, Seeman P. Antipsychotic agents differ in how fast they come off the dopamine D2 receptors. Implications for atypical antipsychotic action. J. Psychiatry Neurosci. 2000; 25:161-166. [PubMed: 10740989]

Kuznetsov AS, Kopell NJ, Wilson CJ. Transient high-frequency firing in a coupled-oscillator model of the mesencephalic dopaminergic neuron. J. Neurophysiol. 2006; 95:932-937. [PubMed: 16207783]

Kuznetsova AY, Huertas MA, Kuznetsov AS, Paladini CA, Canavier CC. Regulation of the firing frequency in a computational model of a midbrain dopaminergic neuron. J. Computational Neurosci. 2010; 28:389-403.

Migliore M, Cannia C, Canavier CC. A modeling study suggesting a possible pharmacological target to mitigate the effects of ethanol on reward-related dopaminergic signaling. J. Neurophysiol. 2008; 99(5):2703-2707. [PubMed: 18353916]

Nedergaard S. A Ca ${ }^{2+}$-independent slow after hyperpolarization in substantia nigra compacta neurons. Neurosci. 2004; 125:841-852.

Nedergaard S, Flatman JA, Engberg I. Nifedipine- and omega-conotoxin-sensitive $\mathrm{Ca}^{2+}$ conductances in guinea-pig substantia nigra pars compacta neurones. J Physiol. 1993; 466:727-747. [PubMed: 8410714]

Ping HX, Shepard PD. Apamin-sensitive $\mathrm{Ca}^{2+}$-activated $\mathrm{K}^{+}$channels regulate pacemaker activity in nigral dopamine neurons. NeuroReport. 1996; 7:809-814. [PubMed: 8733751]

Pucak ML, Grace AA. Effects of haloperidol on the activity and membrane physiology of substantia nigra dopamine neurons recorded in vitro. Brain Research. 1996; 713:44-52. [PubMed: 8724974]

Puopolo M, Raviola E, Bean BP. Roles of subthreshold calcium current and sodium current in spontaneous firing of mouse midbrain dopamine neurons. J. Neurosci. 2007; 27:645-656. [PubMed: 17234596]

Richards CD, Shiroyama T, Kitai ST. Electrophysiological and immunocytochemical characteristics of GABA and dopamine neurons in the substantia nigra of the rat. Neuroscience. 1997; 80:545-557. [PubMed: 9284356] 
Schultz W. Predictive reward signal of dopamine neurons. J. Neurophysiol. 1998; 80:1-27. [PubMed: 9658025]

Seutin V, Engel D. Differences in $\mathrm{Na}+$ conductance density and $\mathrm{Na}+$ channel functional properties between dopamine and GABA neurons of the rat substantia nigra. J. Neurophysiol. 2010; 103:3099-3114. [PubMed: 20357070]

Shepard PD, Bunney BS. Repetitive firing properties of putative dopamine-containing neurons in vitro: regulation by an apamin-sensitive $\mathrm{Ca}^{2+}$-activated $\mathrm{K}^{+}$conductance. Exp. Brain Res. 1991; 86:141-150. [PubMed: 1756785]

Shepard PD, Canavier CC, Levitan ES. Ether-a-go-go related gene (ERG) potassium channels: What's all the buzz about? Schizophrenia Bulletin. 2007; 33(6):1263-1269. [PubMed: 17905786]

Tanaka S. Dopaminergic control of working memory and its relevance to schizophrenia: A circuit dynamics perspective. Neurosci. 2006; 139:153-171.

Tucker K, Huertas M, Horn J, Canavier CC, Levitan ES. Pacemaker rate and depolarization block in nigral dopamine neurons: A sodium channel balancing act. J. Neurosci. 2012; 32:14519-14531. [PubMed: 23077037]

Valenti O, Cifelli P, Gill KM, Grace AA. Antipsychotic drugs rapidly induce dopamine neuron depolarization block in a developmental rat model of schizophrenia. J. Neurosci. 2011; 31(34): 12330-12338. [PubMed: 21865475]

White FJ, Wang RY. Differential effects of classical and atypical antipsychotic drugs on A9 and A10 dopamine neurons. Science. 1983a; 221:1054-1057. [PubMed: 6136093]

White FJ,Wang RY. Comparison of the effects of chronic haloperidol treatment on A9 and A10 dopamine neurons in the rat. Life Sci. 1983b; 32:983-993. [PubMed: 6827927]

Wilson CJ, Callaway JC. Coupled oscillator model of the dopaminergic neuron on the substantia nigra. J. Neurophysiol. 2000; 83:3084-3100. [PubMed: 10805703]

\section{Appendix. Full Model Equations and Parameters}

The voltage-gated currents were modeled as follows:

$\mathrm{I}_{\mathrm{Na}}=\mathrm{g}_{\mathrm{Na}} m^{3} h h_{s}(\mathrm{v}-60), \mathrm{I}_{\mathrm{Ca}, \mathrm{L}}=\mathrm{g}_{\mathrm{Ca}, \mathrm{L}} l(\mathrm{v}-63), \mathrm{I}_{\mathrm{K}, \mathrm{DR}}=\mathrm{g}_{\mathrm{K}, \mathrm{DR}} n^{3}(\mathrm{v}+85)$, and $\mathrm{I}_{\mathrm{H}}=\mathrm{gH} m_{\mathrm{H}}(\mathrm{v}+34.25)$, where the gating variables $l, n, m, h, h_{s}$ and $m_{H}$ obey equations of the form dx/ $\mathrm{dt}=\left(\mathrm{x}_{\text {inf }}-\mathrm{x}\right) / \tau_{\mathrm{x}}$, with $\mathrm{x}_{\text {inf }}=1 /\left[1+\exp \left(-\left(\mathrm{v}-\mathrm{x}_{\text {half }}\right) / \mathrm{x}_{\mathrm{k}}\right)\right]$. Parameters are given in Table 2.

$\mathrm{I}_{\mathrm{K}, \mathrm{M}}=\mathrm{g}_{\mathrm{K}, \mathrm{M}} q(\mathrm{v}+85)$

$\mathrm{d} q / \mathrm{dt}=\mathrm{a}_{\mathrm{q}}(1-q)-\beta_{\mathrm{q}} q$

where $\alpha_{\mathrm{q}}=0.02 /(1+\exp (-(\mathrm{v}+20) / 5))$ and $\beta_{\mathrm{q}}=0.01 * \exp (-(\mathrm{v}+43) / 18)$

$\mathrm{I}_{\mathrm{K}, \mathrm{ERG}}=\mathrm{g}_{\mathrm{K}, \mathrm{RRG}} o(\mathrm{v}+85)$

$\mathrm{d} o / \mathrm{dt}=\mathrm{a}_{\mathrm{a}}(1-o-i)+\beta_{\mathrm{i}} \mathrm{i}-\left(\mathrm{a}_{\mathrm{i}}+\beta_{\mathrm{a}}\right) o$

$\mathrm{d} i / \mathrm{dt}=\mathrm{a}_{\mathrm{i}} O-\beta_{\mathrm{i}} i$,

where $o$ and $i$ are the fraction of open and inactivated channels, respectively with transition rates given by $a_{a}=0.0061 \exp (0.1085 \mathrm{v}), \beta_{\mathrm{a}}=2.1469 \mathrm{e}-05 \exp (-0.0570 \mathrm{v}), \mathrm{a}_{\mathrm{i}}=$ $227.775 \exp (0.1123 \mathrm{v})$ and $\beta_{\mathrm{i}}=21 \exp (0.0712 \mathrm{v})$.

The "leak current" was actually modeled as a combination of an inward rectifying potassium current $\mathrm{I}_{\mathrm{K}, \mathrm{IR}}$, a sodium leak channel $\left(\mathrm{I}_{\mathrm{L}, \mathrm{Na}}\right)$, and a small calcium leak $\left(\mathrm{I}_{\mathrm{L}, \mathrm{Ca}}\right)$,required for the calcium balance. 


$$
\begin{aligned}
& \mathrm{I}_{\mathrm{L}}=\mathrm{I}_{\mathrm{K}, \mathrm{IR}}+\mathrm{I}_{\mathrm{L}, \mathrm{Na}}+\mathrm{I}_{\mathrm{L}, \mathrm{Ca} .}, \mathrm{I}_{\mathrm{K}, \mathrm{IR}}=\mathrm{g}_{\mathrm{K}, \mathrm{IR}}(\mathrm{v}+85) /(1+\exp ((\mathrm{v}+45) / 20)), \mathrm{I}_{\mathrm{L} . \mathrm{Na}}=\mathrm{g}_{\mathrm{L}, \mathrm{Na}}(\mathrm{v}-60), \\
& \mathrm{I}_{\mathrm{L}, \mathrm{Ca}}=\mathrm{g}_{\mathrm{L}, \mathrm{Ca}}(\mathrm{v}-63)
\end{aligned}
$$

The soma, proximal dendrites and distal dendrites are modeled as cylindrical with diameters denoted as $d_{s}, d_{p}$ and $d_{d}$, respectively $\left(d_{d}=1.5 \mu m, d_{p}=3 \mu \mathrm{m}\right.$, and $\left.d_{s}=15 \mu \mathrm{m}\right) . L_{s}, L_{p}$ and $L_{d}$ denote their lengths $\left(\mathrm{L}_{\mathrm{d}}=350 \mu \mathrm{m}, \mathrm{L}_{\mathrm{p}}=150 \mu \mathrm{m}\right.$ and $\left.\mathrm{L}_{\mathrm{s}}=25 \mu \mathrm{m}\right)$. The total resistance between the soma and each proximal dendrite is $\mathrm{R}_{\mathrm{sp}}=0.5 \mathrm{~L}_{\mathrm{s}} \mathrm{R}_{\mathrm{a}} /\left(0.25 \pi \mathrm{d}_{\mathrm{s}}{ }^{2} \mathrm{~L}_{\mathrm{s}}\right)+0.5 \mathrm{~L}_{\mathrm{p}} \mathrm{R}_{\mathrm{a}} /\left(0.25 \pi \mathrm{d}_{\mathrm{p}}{ }^{2} \mathrm{~L}_{\mathrm{p}}\right)$, and the total conductance is $G_{s p}=1 / R_{s p}$. The intensive conductances are $g_{s p}=4 G_{s p} / \pi d_{s} L_{s}$ and $g_{p s}=G_{s p} / \pi d_{p} L_{p}$, where the factor of 4 reflects that there are four proximal dendrites but only one soma. The axial current in intensive units flowing into the soma from all four proximal dendrites is $\mathrm{I}_{\mathrm{sp}}=\mathrm{g}_{\mathrm{sp}}\left(\mathrm{V}_{\mathrm{s}}-\mathrm{V}_{\mathrm{p}}\right)$. The axial current for an individual proximal dendrite is $\mathrm{I}_{\mathrm{ps}}=\mathrm{g}_{\mathrm{ps}} *\left(\mathrm{~V}_{\mathrm{p}}-\mathrm{V}_{\mathrm{s}}\right)$. Similarly, the total resistance between the proximal dendrites and each distal dendrite is $\mathrm{R}_{\mathrm{pd}}=0.5 \mathrm{~L}_{\mathrm{d}} \mathrm{R}_{\mathrm{a}} /\left(0.25 \pi \mathrm{d}_{\mathrm{d}}{ }^{2} \mathrm{~L}_{\mathrm{d}}\right)+0.5 \mathrm{~L}_{\mathrm{p}} \mathrm{R}_{\mathrm{a}} /\left(0.25 \pi \mathrm{d}_{\mathrm{p}}{ }^{2} \mathrm{~L}_{\mathrm{p}}\right)$, and the total conductance is $\mathrm{G}_{\mathrm{pd}}=1 / \mathrm{R}_{\mathrm{pd}}$. The intensive conductances are $\mathrm{g}_{\mathrm{pd}}=2 \mathrm{G}_{\mathrm{pd}} / \pi \mathrm{d}_{\mathrm{p}} \mathrm{L}_{\mathrm{p}}$ and $\mathrm{g}_{\mathrm{dp}}=$ $\mathrm{G}_{\mathrm{pd}} / \pi \mathrm{d}_{\mathrm{d}} \mathrm{L}_{\mathrm{d}}$, where the factor of 2 reflects that there are two distal dendrites for each proximal one. The axial current in intensive units flowing into the proximal dendrite from both of its distal dendrites is $I_{p d}=g_{p d}\left(V_{p}-V_{d}\right)$. The axial current for an individual distal dendrite is $I_{d p}$ $=\mathrm{g}_{\mathrm{dp}} *\left(\mathrm{~V}_{\mathrm{d}}-\mathrm{V}_{\mathrm{p}}\right)$.

The differential equations for transmembrane potential are as follows:

$$
\begin{aligned}
& C \mathrm{dV}_{\mathrm{s}} / \mathrm{dt}=-\mathrm{I}_{\mathrm{Na}, \mathrm{s}}-\mathrm{I}_{\mathrm{K}, \mathrm{DR}, \mathrm{s}}-\mathrm{I}_{\mathrm{K}, \mathrm{M}, \mathrm{s}}-\mathrm{I}_{\mathrm{K}, \mathrm{ERG}, \mathrm{s}}-\mathrm{I}_{\mathrm{K}, \mathrm{SK}, \mathrm{s}}-\mathrm{I}_{\mathrm{Ca}, \mathrm{L}, \mathrm{s}}-\mathrm{I}_{\mathrm{L}, \mathrm{Na}, \mathrm{s}}-\mathrm{I}_{\mathrm{L}, \mathrm{Ca}, \mathrm{s}}- \\
& \mathrm{I}_{\mathrm{GIRK}, \mathrm{s}}-\mathrm{I}_{\mathrm{H}, \mathrm{s}}+\mathrm{I}_{\mathrm{stim}}-\mathrm{I}_{\mathrm{sp}}+\mathrm{I}_{\mathrm{NMDA}} \\
& \mathrm{CdV_{ \textrm {p } }} / \mathrm{dt}=-\mathrm{I}_{\mathrm{Na}, \mathrm{p}}-\mathrm{I}_{\mathrm{K}, \mathrm{DR}, \mathrm{p}}-\mathrm{I}_{\mathrm{K}, \mathrm{M}, \mathrm{p}}-\mathrm{I}_{\mathrm{K}, \mathrm{ERG}, \mathrm{p}}-\mathrm{I}_{\mathrm{K}, \mathrm{SK}, \mathrm{p}}-\mathrm{I}_{\mathrm{Ca}, \mathrm{L}, \mathrm{p}}-\mathrm{I}_{\mathrm{L}, \mathrm{Na}, \mathrm{p}}-\mathrm{I}_{\mathrm{L}, \mathrm{Ca}, \mathrm{p}}- \\
& \mathrm{I}_{\mathrm{GIRK}, \mathrm{p}}-\mathrm{I}_{\mathrm{H}, \mathrm{p}}-\mathrm{I}_{\mathrm{ps}}-\mathrm{I}_{\mathrm{pd}} \\
& \mathrm{CdV_{ \textrm {d } }} / \mathrm{dt}=-\mathrm{I}_{\mathrm{Na}, \mathrm{d}}-\mathrm{I}_{\mathrm{K}, \mathrm{DR}, \mathrm{d}}-\mathrm{I}_{\mathrm{K}, \mathrm{M}, \mathrm{d}}-\mathrm{I}_{\mathrm{K}, \mathrm{ERG}, \mathrm{d}}-\mathrm{I}_{\mathrm{K}, \mathrm{SK}, \mathrm{d}}-\mathrm{I}_{\mathrm{Ca}, \mathrm{L}, \mathrm{d}}-\mathrm{I}_{\mathrm{L}, \mathrm{Na}, \mathrm{d}}-\mathrm{I}_{\mathrm{L}, \mathrm{Ca}, \mathrm{d}}- \\
& \mathrm{I}_{\mathrm{GIRK}, \mathrm{d}}-\mathrm{I}_{\mathrm{H}, \mathrm{d}}-\mathrm{I}_{\mathrm{dp}}
\end{aligned}
$$

The calcium balance is given by

$$
\begin{aligned}
& \mathrm{d}[\mathrm{Ca}] / \mathrm{dt}=-2 \mathrm{f}_{\mathrm{Ca}}\left(\mathrm{I}_{\mathrm{L}, \mathrm{Ca}}+\mathrm{I}_{, \mathrm{Ca}, \mathrm{p}}+\mathrm{I}_{\mathrm{Ca}, \mathrm{L}}\right) / \mathrm{Fd} \\
& \mathrm{I}_{\mathrm{Ca}, \mathrm{p}}=\mathrm{I}_{\mathrm{Ca}, \mathrm{p} \_ \text {, } m a x} /(1+1 /(0.00055 /[\mathrm{Ca}]))
\end{aligned}
$$

where [Ca] (in $\mathrm{mM}$ ) is the $\mathrm{Ca}^{2+}$ concentration in each compartment, $\mathrm{f}_{\mathrm{Ca}}=0.015$ is the fraction of free calcium, $d$ is the diameter of the compartment and $\mathrm{F}$ is Faraday's constant. Extrusion of $\mathrm{Ca}^{2+}$ from the compartments is modeled as a nonelectrogenic pump with $\mathrm{I}_{\mathrm{Ca}, \mathrm{p} \_ \text {max }}=6 \mu \mathrm{A} / \mathrm{cm}^{2}$.

The calcium dependent conductance was modeled as

$$
\mathrm{I}_{\mathrm{K}, \mathrm{SK}}=\mathrm{g}_{\mathrm{K}, \mathrm{SK}}(\mathrm{v}+85) /\left(1+(0.00019 /[\mathrm{Ca}])^{4}\right) .
$$

And the virtual NMDA conductance was modeled as

$$
\mathrm{I}_{\mathrm{NMDA}}=-\mathrm{g}_{\mathrm{NMDA}}{ }^{*} \mathrm{v} /(1+(\mathrm{Mg} / 3.57) * \exp (-0.062 \mathrm{v})) \text { where } \mathrm{Mg}=1.5 \mathrm{mM} \text {. }
$$

Maximal conductances in $\mu \mathrm{S} / \mathrm{cm}^{2}$ were $\mathrm{g}_{\mathrm{Na}}=2300, \mathrm{~g}_{\mathrm{K}}=1200, \mathrm{~g}_{\mathrm{Lca}}=19.8, \mathrm{~g}_{\text {girk }}=32.5$, $\mathrm{g}_{\mathrm{Na}, \text { leak }}=2.1, \mathrm{~g}_{\mathrm{K}, \mathrm{ERG}}=115, \mathrm{~g}_{\mathrm{SK}}=300, \mathrm{~g}_{\mathrm{KM}}=40, \mathrm{~g}_{\text {Ca, leak }}=0.05, \mathrm{~g}_{\mathrm{H}}=20$. 
A

$\left[\begin{array}{l}\text { E } \\ 0\end{array}\right.$

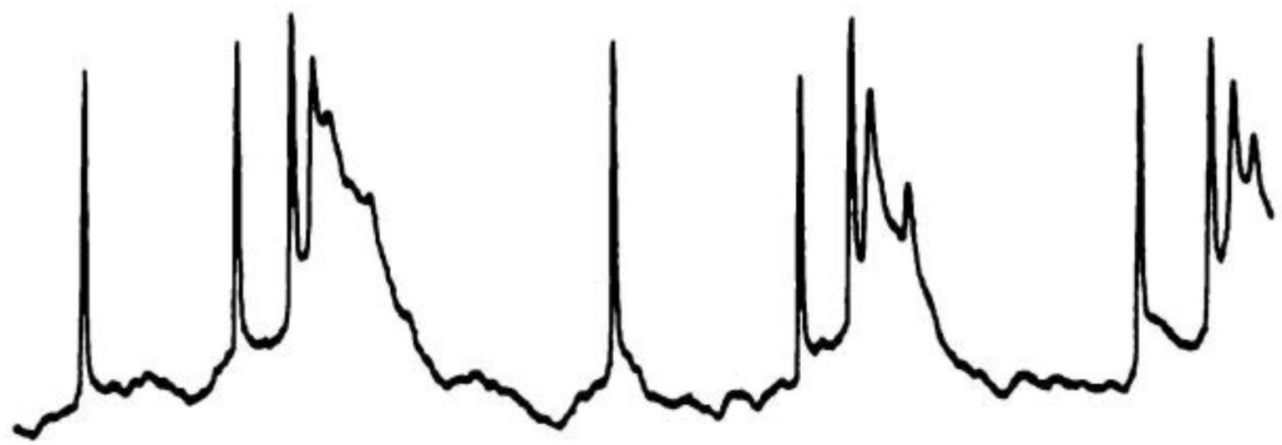

B

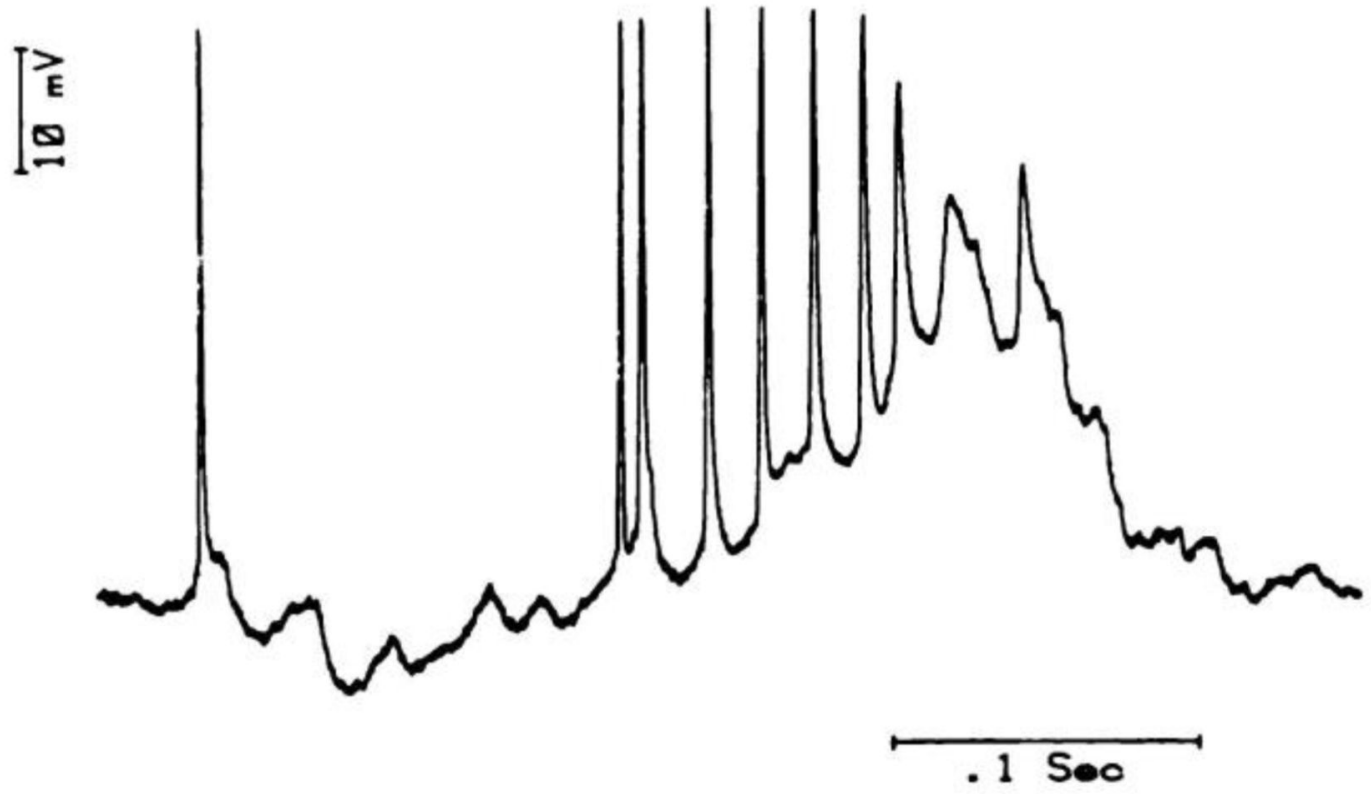

Figure 1.

Intracellular recordings of spontaneously firing DA neurons in haloperidol-treated rats. Although most of the DA neurons in treated rats are not spontaneously active, a few firing neurons may nonetheless be impaled with a recording electrode. These neurons typically demonstrate rapid, high-amplitude burst activity unlike that commonly observed in DA neurons in control animals. A, rapid, high-amplitude bursting in a DA cell presumably on the threshold of depolarization block. B, a DA cell in a less depolarized state. Final spikes in 
burst are inactivated. Reproduced with permission from Figure 2 of Grace and Bunney 1986 with the original figure caption. 
A

\section{Extracellular Fluid}

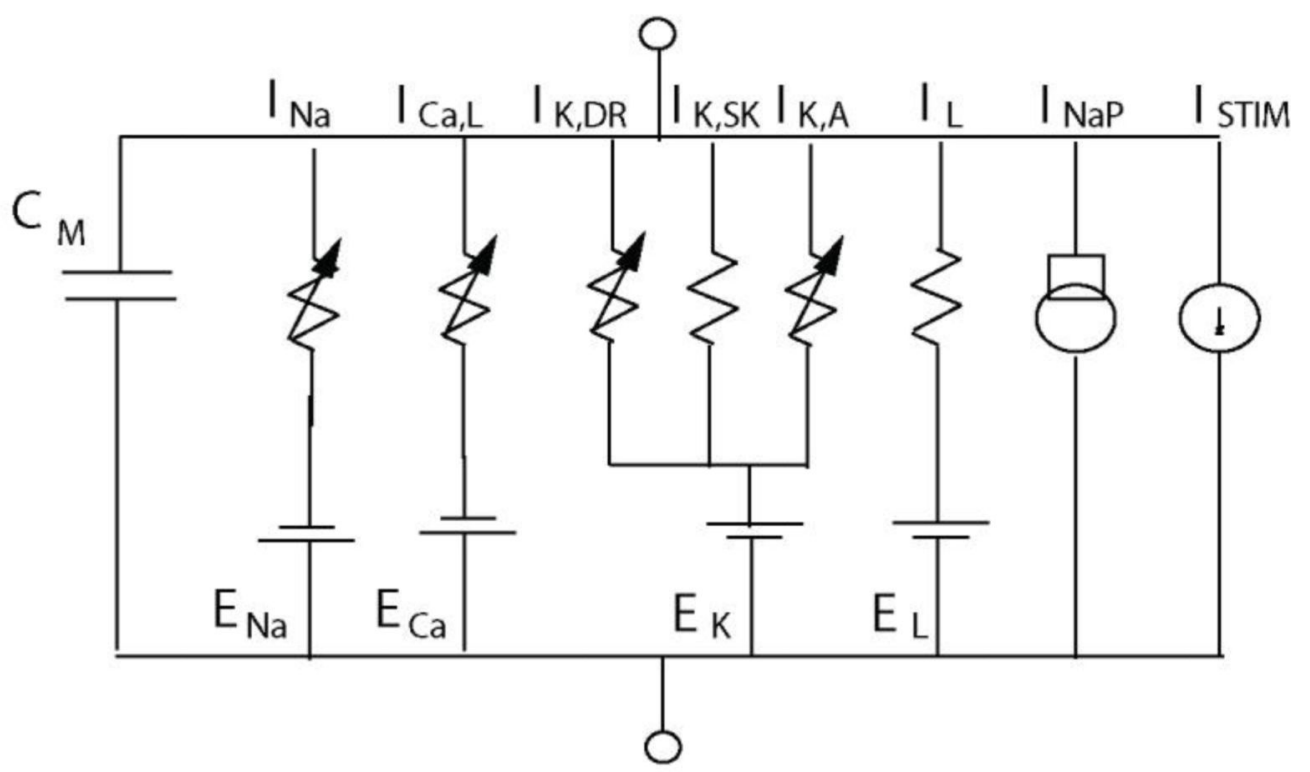

B

Intracellular Fluid
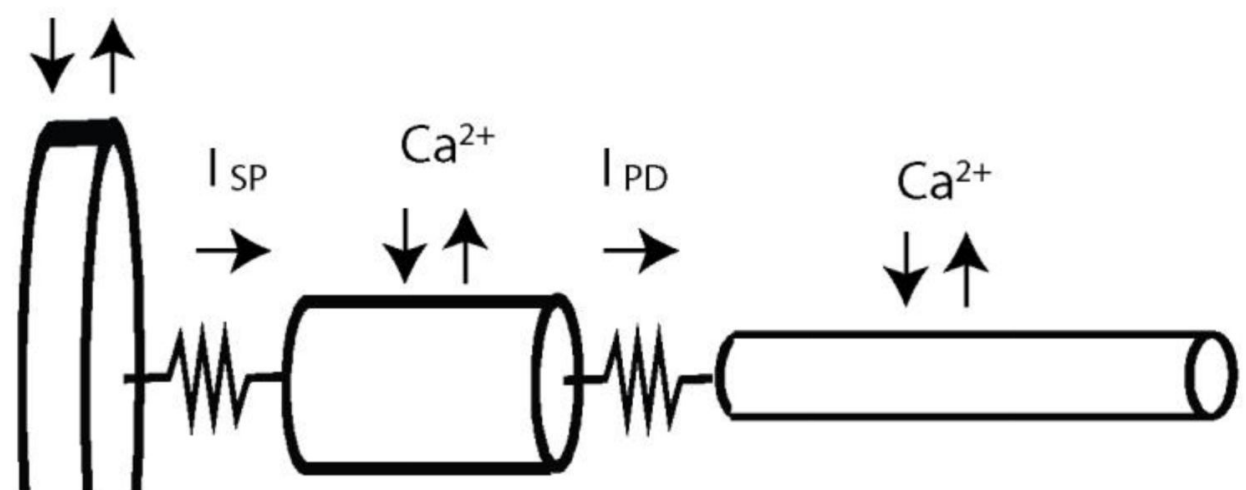

Soma

Proximal Dendrite
Distal

Dendrite

Figure 2.

Model of dopamine neuron as a spiking pacemaker. A. Conductance-based equivalent circuit for each compartment ( $\mathrm{I}_{\mathrm{stim}}$ is confined to the soma). The arrows indicate time and voltage dependent conductances. B. Schematic representation of the multi-compartmental model and the calcium balance. 

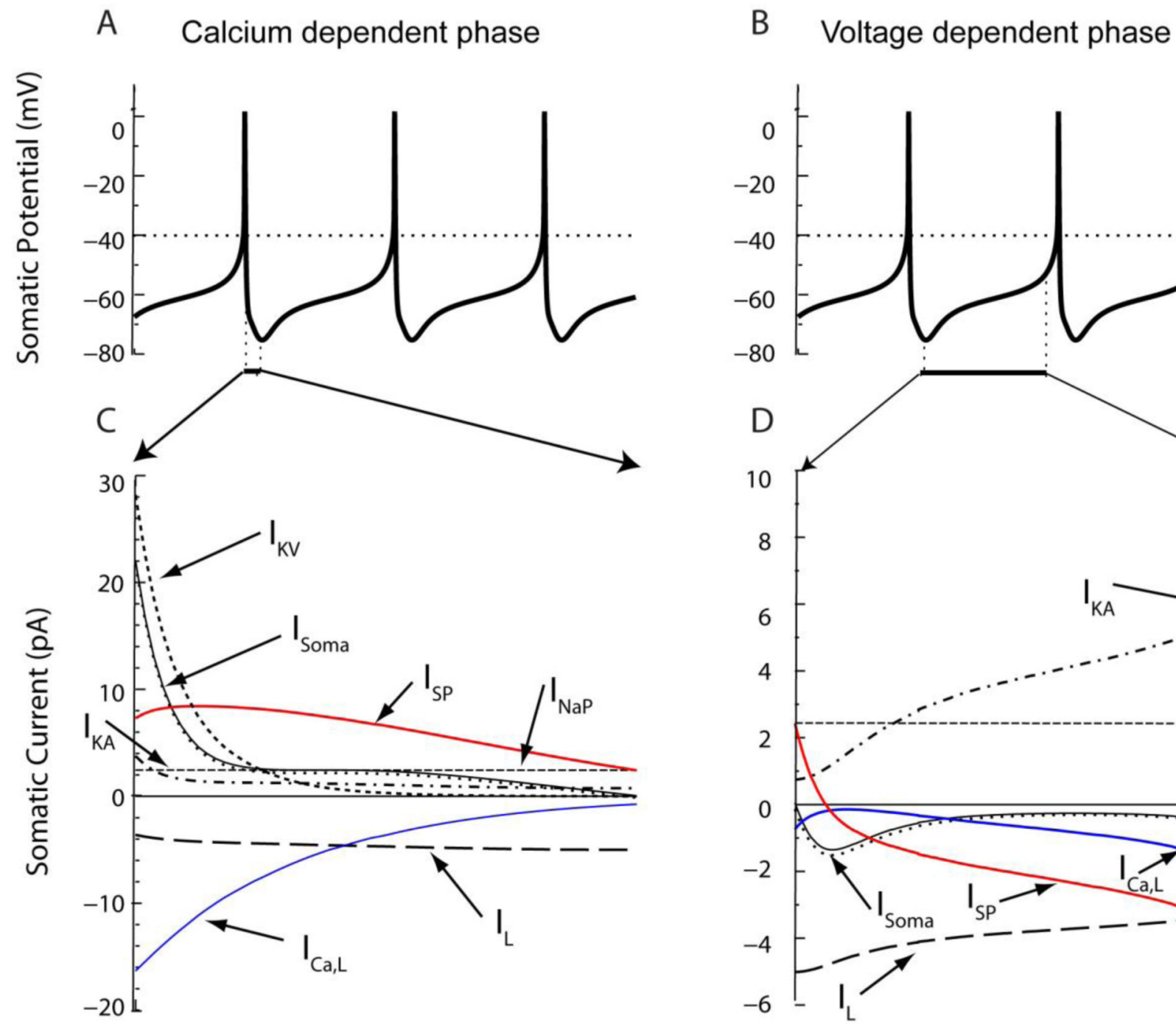

Figure 3.

Currents contributing to AHP and ISI duration. A and B show the somatic membrane potential during spontaneous spiking activity, simulated from schematic DA neuron model. Also indicated is the portion of the interspike interval (ISI) analyzed below. C and D show the most important currents that contribute to the total somatic current during the time intervals of the ISI indicated in panels $\mathrm{A}$ and $\mathrm{B}$. Labeling: $\mathrm{I}_{\mathrm{KA}}$, hyperpolarization activated $\mathrm{K}^{+}$current; $\mathrm{I}_{\mathrm{NaP}}$, electrogenic $\mathrm{Na}^{+}$pump; $\mathrm{I}_{\mathrm{Ca}, \mathrm{L}}, \mathrm{Ca}^{2+} \mathrm{L}$-type channel current, $\mathrm{I}_{\mathrm{SP}}$ dendritic current; $\mathrm{I}_{\mathrm{L}}$, leak current; $\mathrm{I}_{\text {Soma }}$, net contribution from $\mathrm{I}_{\mathrm{KA}}, \mathrm{I}_{\mathrm{NaP}}, \mathrm{I}_{\mathrm{Ca}, \mathrm{L}}, \mathrm{I}_{\mathrm{SP}}$ and $\mathrm{I}_{\mathrm{L}}$ to total somatic current is indicated by solid curve. The total somatic current was obtained by multiplying the somatic current densities in the model by the somatic surface area. Reproduced from Figure 3 of Kuznetsova et al., 2010 with kind permission from Springer Science and Business Media. 

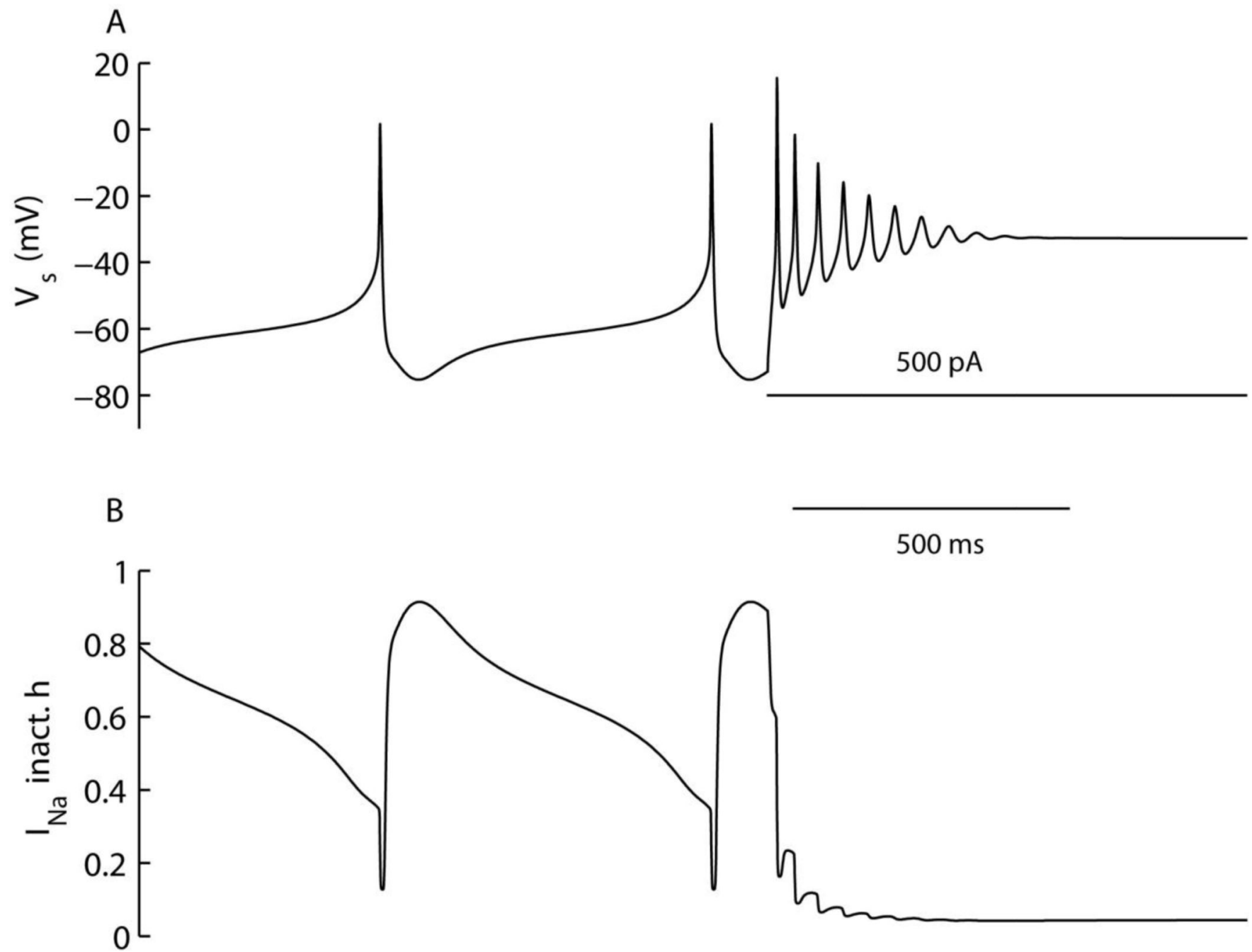

Figure 4.

Simulated induction of depolarization block by simulated somatic current injection. A:

Somatic membrane potential trace from schematic DA neuron model under control conditions before simulated applied current and during application of $500 \mathrm{pA}$ pulse. In the latter case a cessation of the spiking response is observed. B) Inactivation variable $(h)$ of fast $\mathrm{Na}+$ current as a function of time for the simulation in A. At the larger value of applied current the inactivation of $\mathrm{Na}^{+}$current is not removed leading to depolarization block. Adapted with permission from Figure 6 in Kuznetsova et al., 2010. 


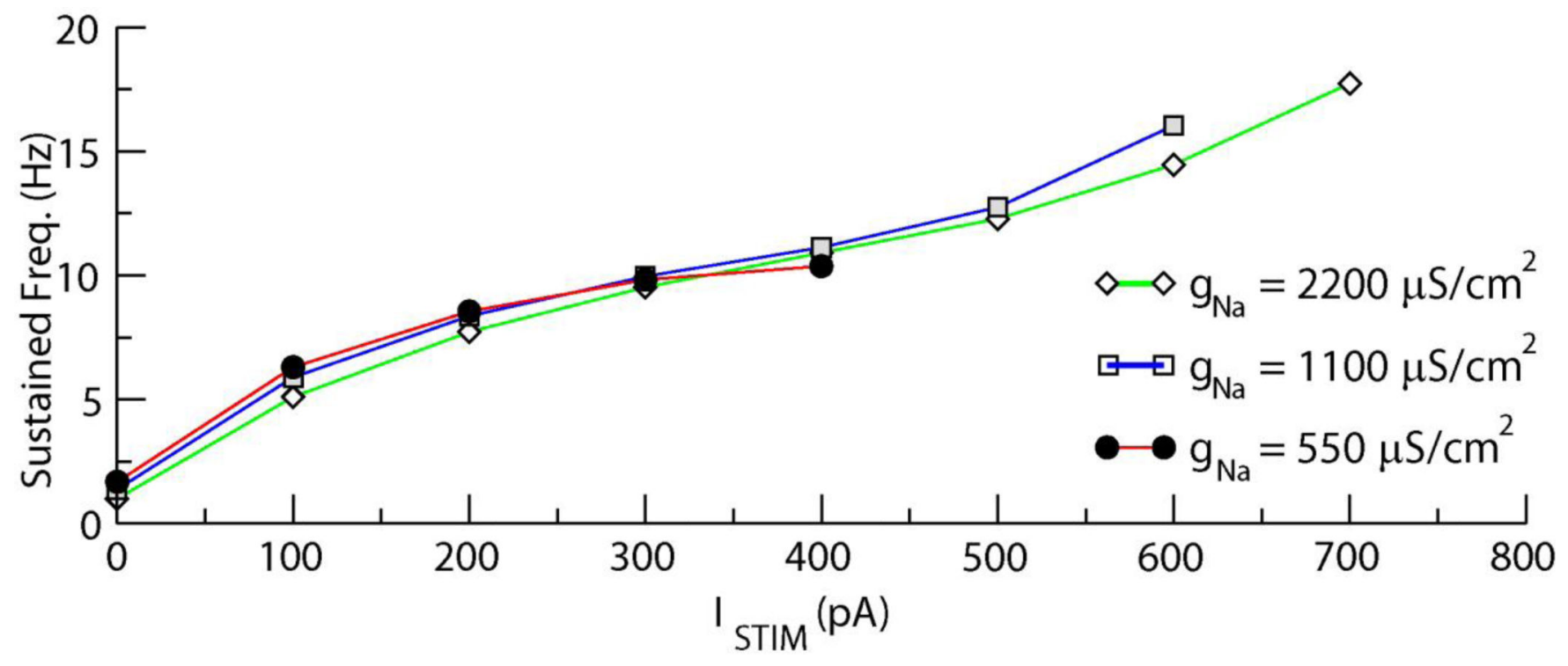

Figure 5 .

Spiking current conductance densities control the maximum frequency in the schematic model. Frequency current plots at different levels of sodium conductance density $\left(\mathrm{g}_{\mathrm{Na}}\right)$. Adapted with permission from Figure 8 (a) in Kuznetsova et al., 2010. 

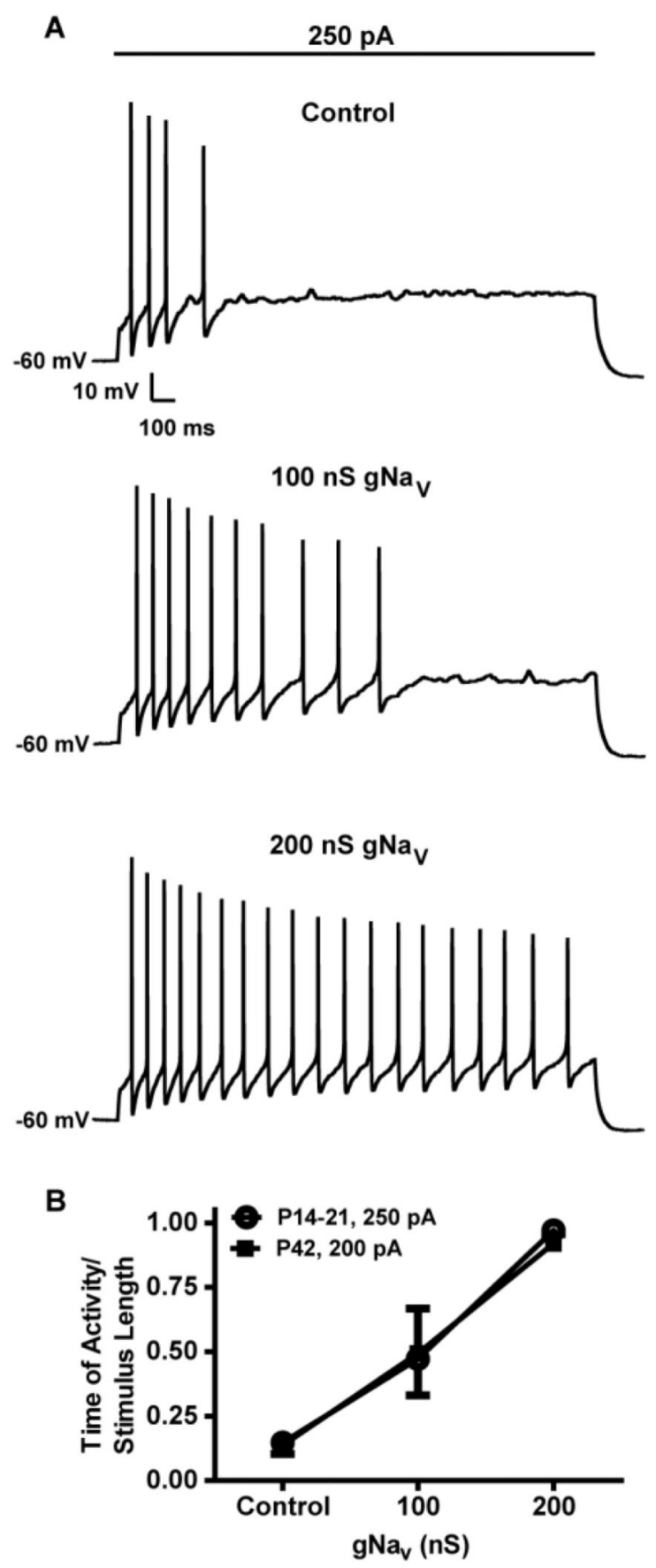

Figure 6.

Additional somatic $\mathrm{Na}_{V}$ channels reduce DP block produced by current injection in adolescent and older animals. Representative recordings from SNc DA neurons currentclamped at $-60 \mathrm{mV}$ followed by (A) a $2 \mathrm{~s}, 250 \mathrm{pA}$ current injection to induce DP block under control conditions (top) and with $100 \mathrm{nS}$ (middle) or $200 \mathrm{nS}$ (bottom) of virtual Nav added via dynamic clamp. B) Resistance to DP block as quantified by length of activity divided by the stimulus length plotted against the virtual $\mathrm{Na}_{\mathrm{V}}$ conductance in response to a current injection. Current injections were $250 \mathrm{pA}$ for SN DA neurons in slices from P14 - 
P21 rats (open circles; $n=11$ ) and $200 \mathrm{pA}$ current injection to SN DA neuron in slices from a P42 rat (black square; $n=3$ ). Symbols and error bars indicate the mean \pm SEM. Adapted with permission from Figure 5 Tucker et al., 2012. 

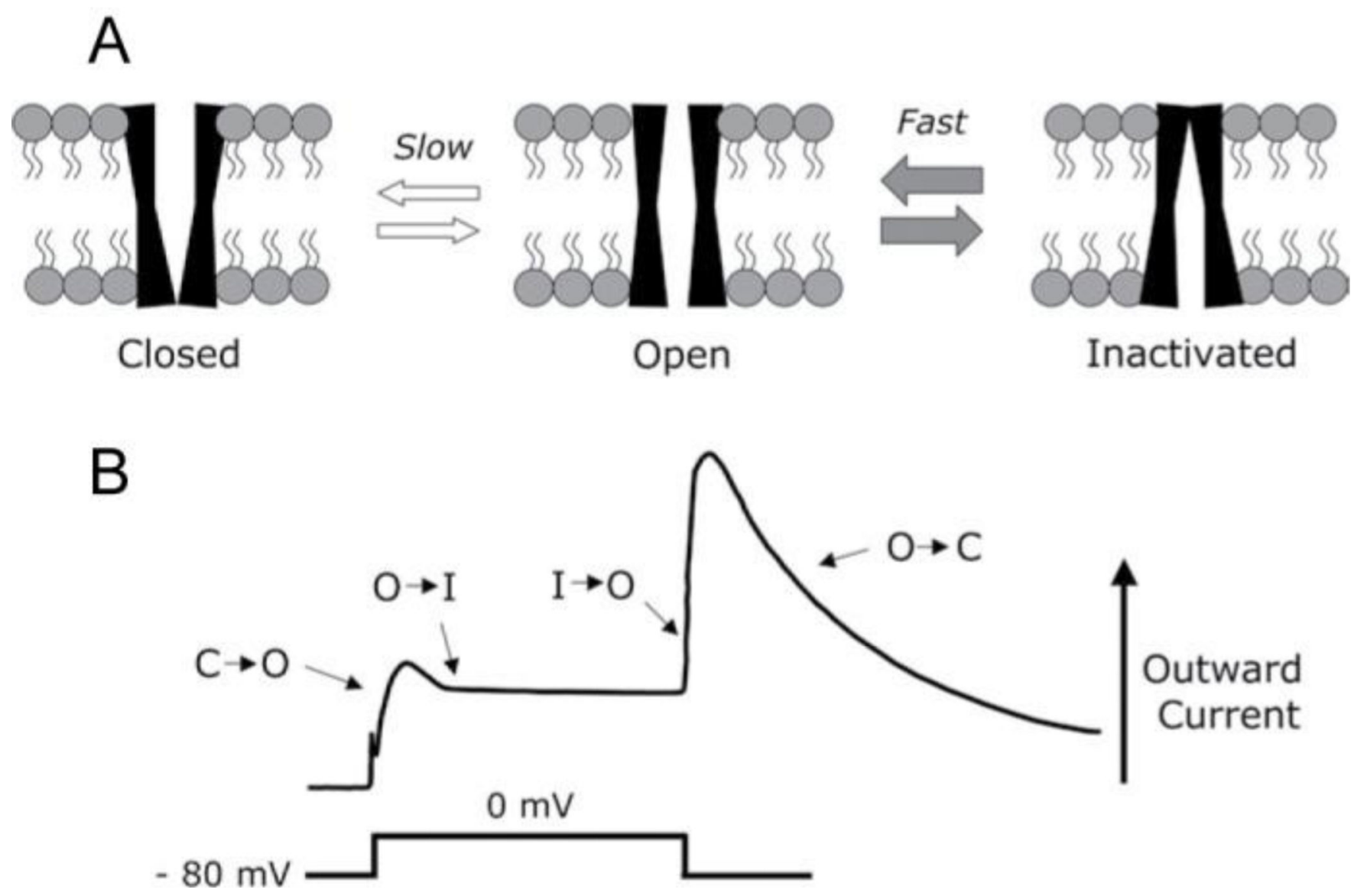

Figure 7.

Voltage-dependent characteristics of ERG $\mathrm{K}^{+}$channels. A: Cartoon schematic illustrating the three conductance states of ERG $\mathrm{K}^{+}$channels. B: Macroscopic current corresponding to the conductance states in illustrated A. At hyperpolarized membrane potentials, ERG channels are closed (C). Depolarizing the membrane potential from $-80 \mathrm{mV}$ to $0 \mathrm{mV}$ (lower trace) slowly opens the channels $(\mathrm{C} \rightarrow \mathrm{O})$ resulting in an initial outward current as $\mathrm{K}^{+}$ions diffuse out of the cell. However, ERG channels rapidly inactivate $(\mathrm{O} \rightarrow \mathrm{I})$ by entering a second non-conductive state that limits the outward current produced by the initial depolarization. Partial repolarization of the membrane potential induces a rapid transition from an inactive to an open conformation $(I \rightarrow O)$. Since the rate of deinactivation $(I \rightarrow O)$ exceeds the rate at which the channels can close, a large 'resurgent' current is generated as the membrane potential repolarizes. Reprinted with permission from Figure 1 of Shepard et al., 2007. 

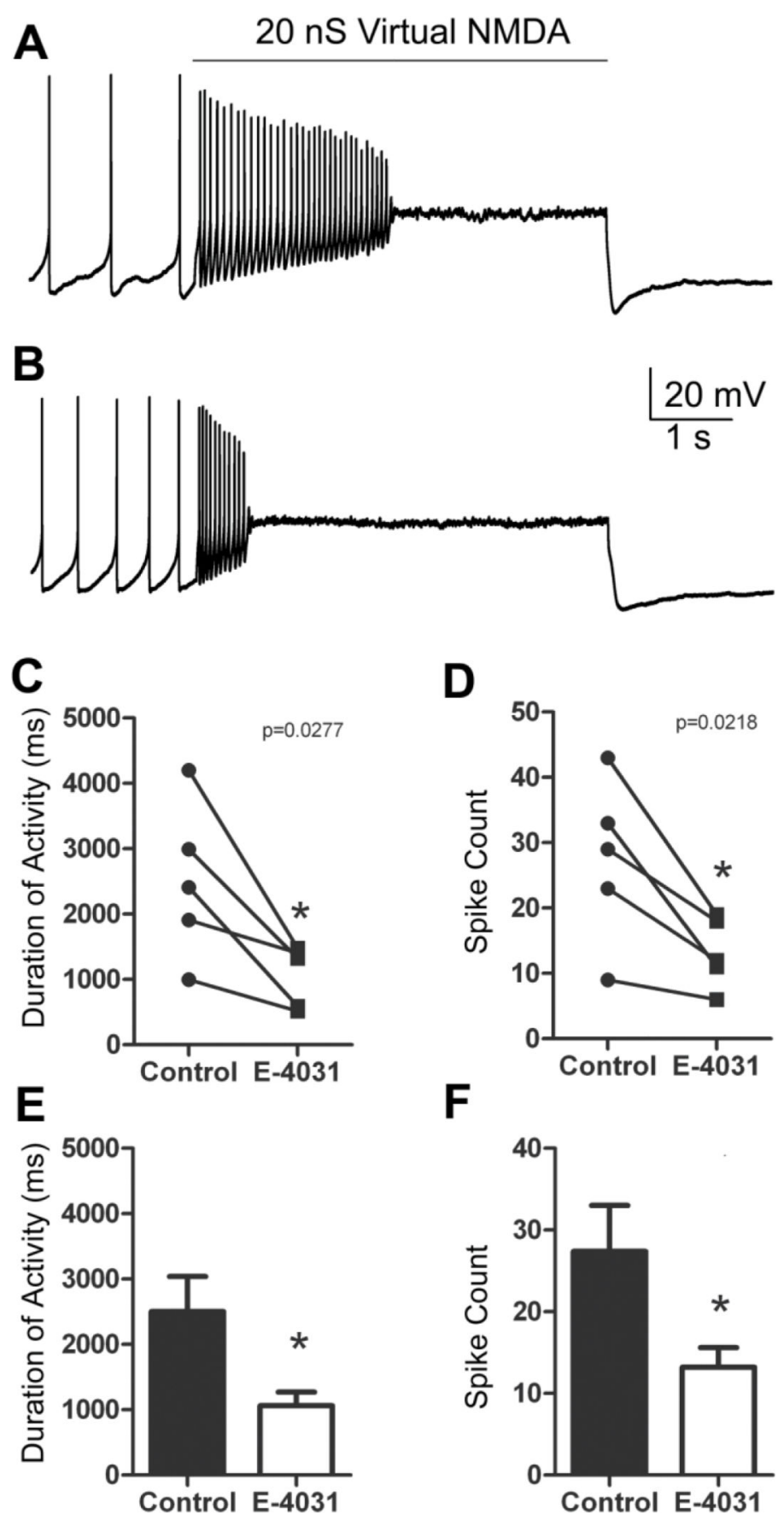

$\mathbf{F}$

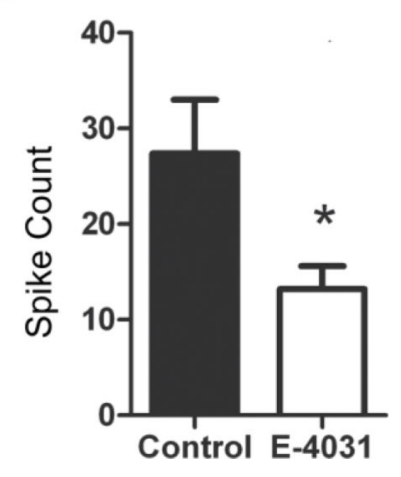

Figure 8.

The prototypical ERG channel blocker E-4031 promotes depolarization block by virtual NMDA receptor stimulation. A and B are representative whole-cell dynamic-clamp recordings of DA neurons stimulated with $20 \mathrm{nS}$ of virtual NMDA current for 5 seconds to induce depolarization block before (A) and after (B) superfusion with $10 \mu \mathrm{M}$ E-4031. The horizontal line above the traces indicates virtual NMDA conductance application. Summary of the effects of $10 \mu \mathrm{M}$ E-4031 on the duration $(C, E)$ and spike count $(D, F)$ from dynamic 
clamp simulations of NMDA-induced bursting activity. ${ }^{*} \mathrm{p}<0.05$. Adapted with permission from Figure 4 of Ji et al., 2012. 

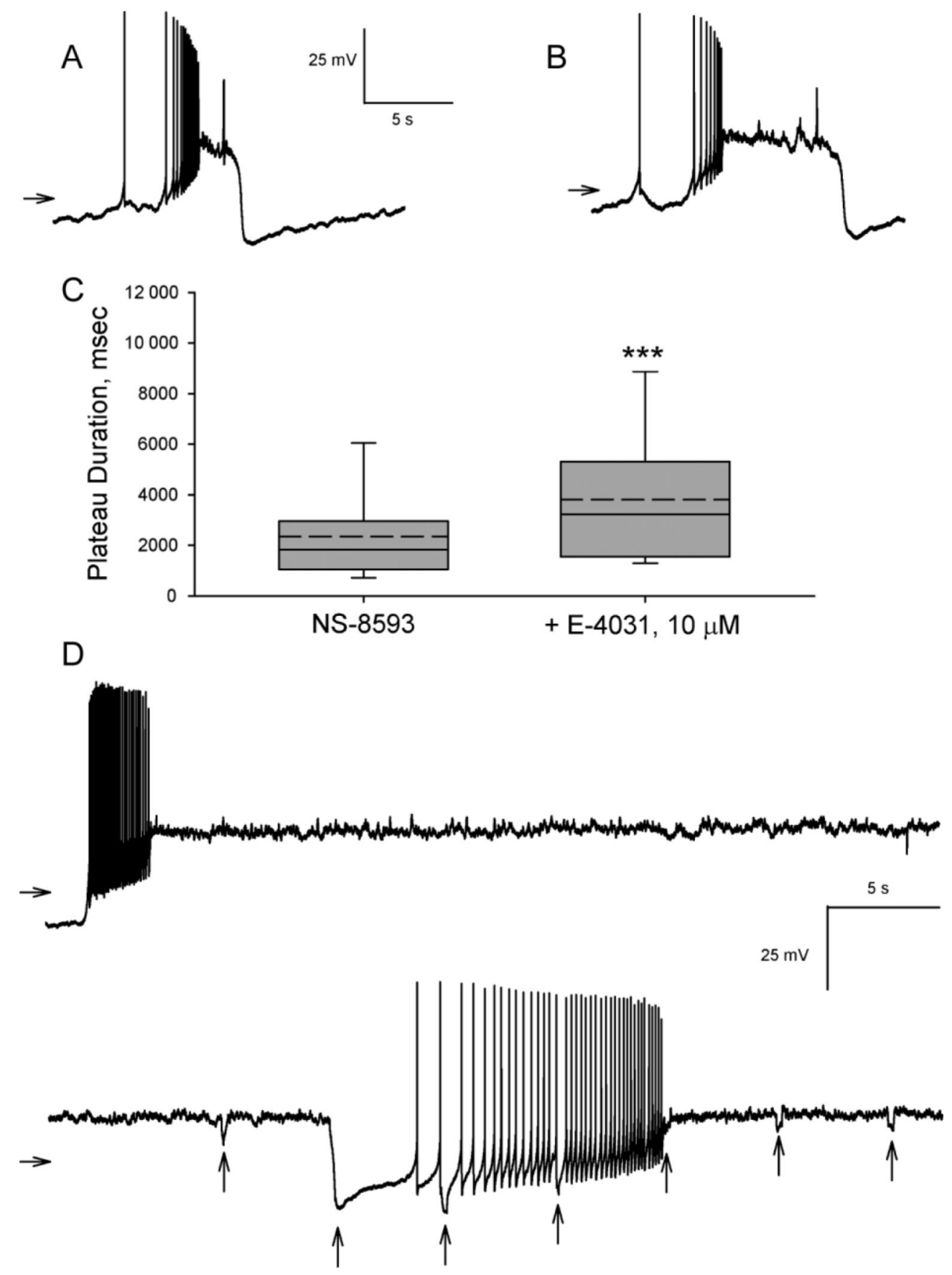

Figure 9.

ERG $\mathrm{K}^{+}$channel block prolongs plateau potentials induced by the SK channel negative modulator, NS8593. A: Representative tracing from a DA neuron in the presence of NS8593 $(6 \mathrm{uM})$. Note the "burst" of action potentials elicited during the initial phase of a depolarizing plateau potential. B: Addition of E-4031 $(10 \mu \mathrm{M})$ prolongs the duration of the plateau. C: Box $\left(25^{\text {th }}\right.$ and $74^{\text {th }}$ percentiles $)$ and whisker $\left(10^{\text {th }}\right.$ and $90^{\text {th }}$ percentiles $)$ plot illustrating the effects of E-4031 $(10 \mu \mathrm{M})$ on the duration of spontaneous plateau potentials elicited by negative modulation of SK channels. Solid and dashed lines inside the box 
represent the median and mean, respectively. $* * * \mathrm{P}<0.003$ vs. NS8593. D: Perfusion with E-4031 $(10 \mu \mathrm{M})$ results in the loss of spontaneous activity through depolarization block following removal of a negative bias current. Brief hyperpolarizing current pulses $(0.03 \mathrm{nA}$, $200 \mathrm{~ms}$; vertical arrows) are capable of repolarizing the neuron which leads to recovery of spontaneous spiking followed by the rapid return of depolarization block. Adapted with permission from Figure 3 of Ji et al., 2012. 


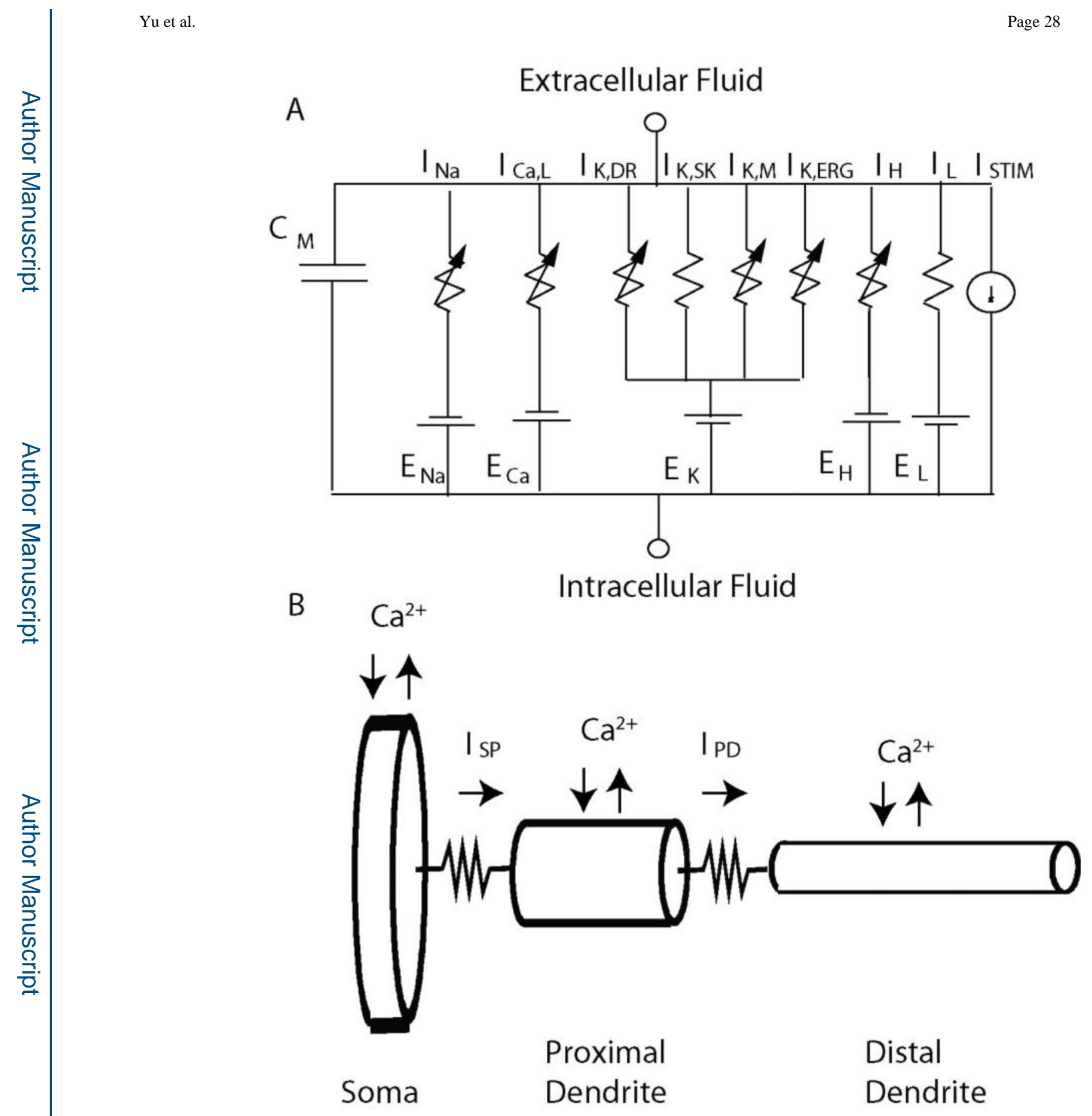

Figure 10.

Model of dopamine neuron extended to simulate bursting and pacing. Details are given in the appendix. 
A1. voltage dependance
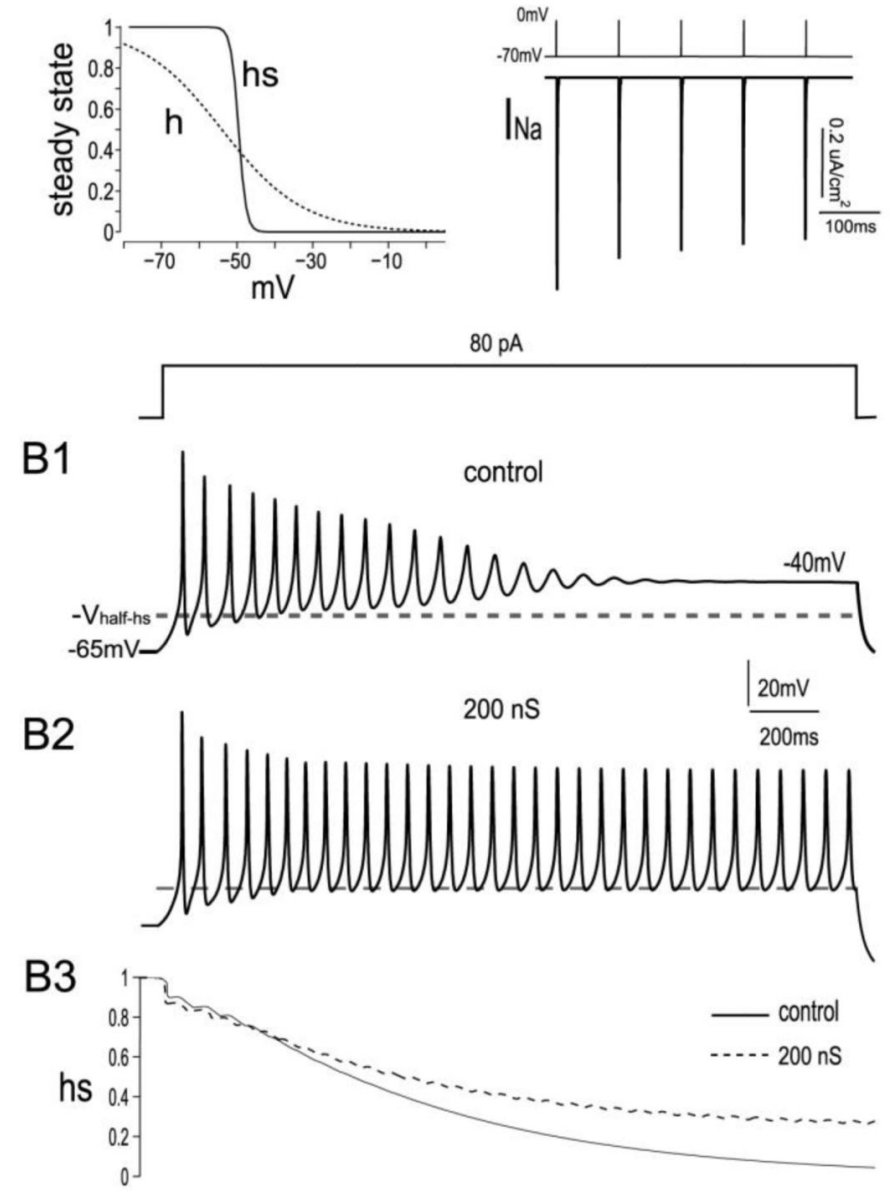

B4

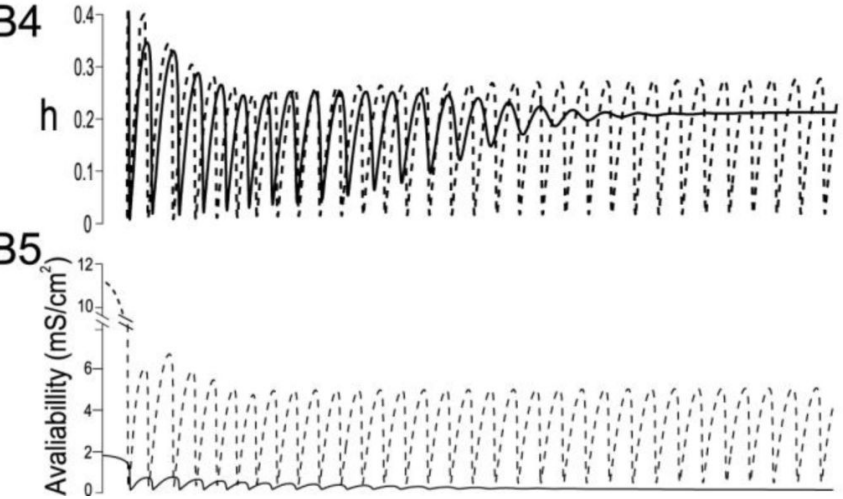

Figure 11.

How additional $\mathrm{Na}_{\mathrm{V}}$ conductance rescues depolarization block. A1) Steady state voltage dependence for fast inactivation $(h)$ and slow inactivation $(h s)$. A2) The peak of the sodium current elicited by a10 $\mathrm{Hz}$ train of $3 \mathrm{msec}$ voltage steps from $-70 \mathrm{mV}$ to $0 \mathrm{mV}$ decays during the train due to accumulation of slow inactivation hs. This simulation mimics the protocol of Figure 8 in Ding et al., 2011. B) This simulation mimics the protocol in Figure 6 in which a 2 second current pulse is applied. B1) Under control conditions, the pulse causes entry into depolarization block. B2) The simulated addition of virtual $\mathrm{Na}_{\mathrm{V}}$ conductance prevents entry 
into depolarization block. B3) The additional conductance allows for more recovery from slow inactivation. B4) At similar levels of $h s$, the recovery under control from $\mathrm{h}$ is similar to that with added $\mathrm{Na}_{\mathrm{V}}$, but deteriorates as the difference in $h s$ is established. B5) The major difference is that the noninactivated (available) conductance after each spike is increased with additional conductance. 


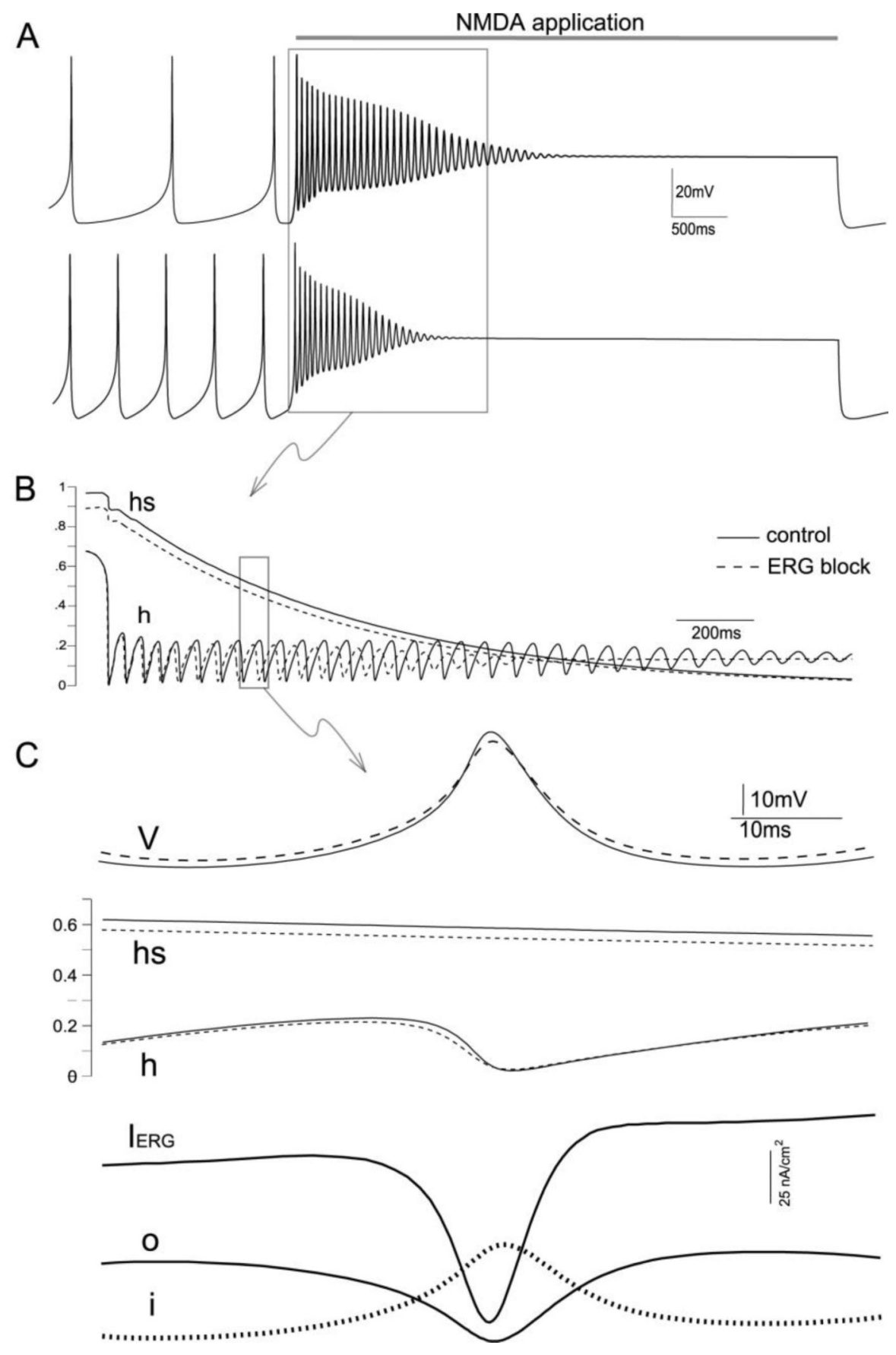

Figure 12.

How the ERG current delays entry into depolarization block. A, Top) A square pulse of simulated virtual NMDA conductance applied to a pacemaking model neuron induces a burst of spikes followed by depolarization block. A, Bottom) Simulated ERG current block increases the pacemaker rate, and accelerates entry into depolarization block, shortening both the bursting duration and the number of spikes in the burst. B) ERG block clearly decreases recovery from slow sodium channel inactivation $(h s)$ during the square pulse in conductance with a more ambiguous effect on fast sodium inactivation $(h)$. The addition of 
ERG channels enhances $h s$, thus the fraction of available sodium channels $\left(h^{*} h s\right)$. C) During a single spike, the potential during the interspike interval is elevated in the absence of the ERG current (dashed trace) compared to control (solid trace), resulting in more slow inactivation (lower levels of hs). The change in the level of $\mathrm{h}$ due to a spike is greater under control conditions due to the extra after hyperpolarization due to the ERG current. The time course of the ERG current and its open state (o), inactivation state $(i)$ is shown for the control case only. 


\section{A1 SK block}

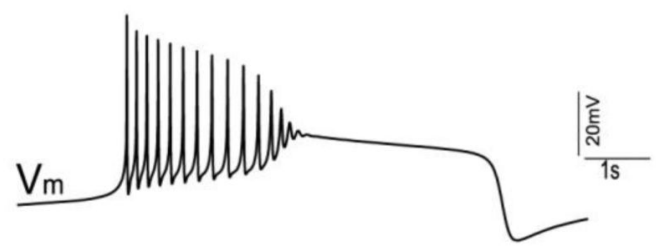

B1
C1
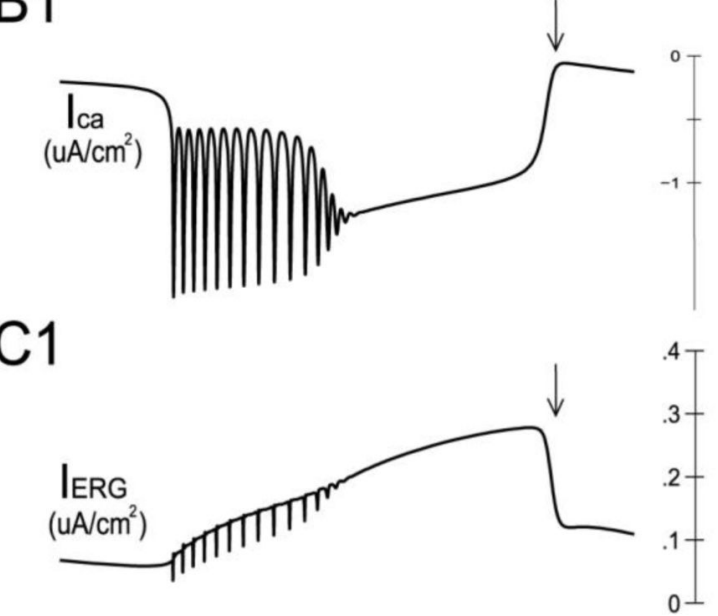

D1

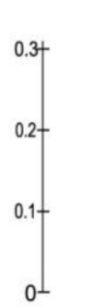

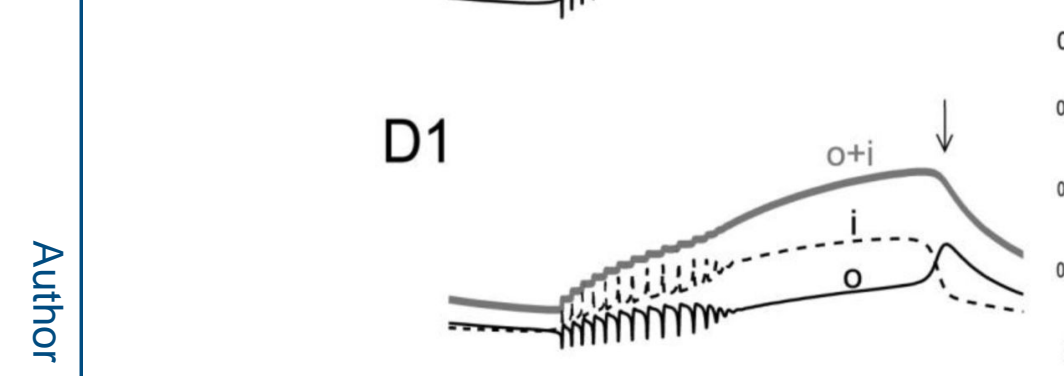

E SK block + ERG block

Figure 13.
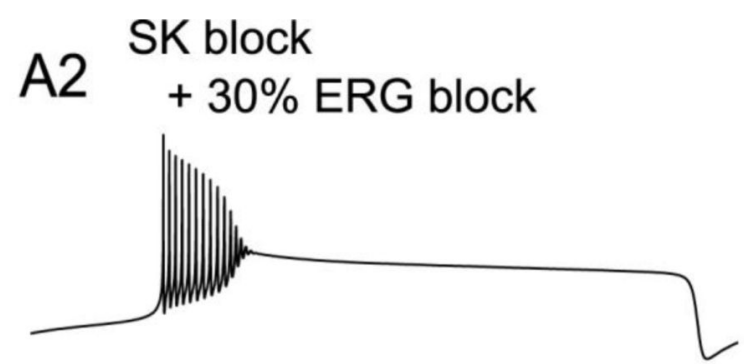

B2

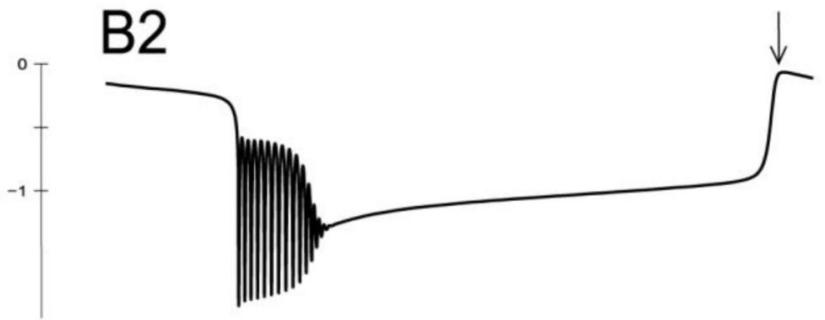

C2
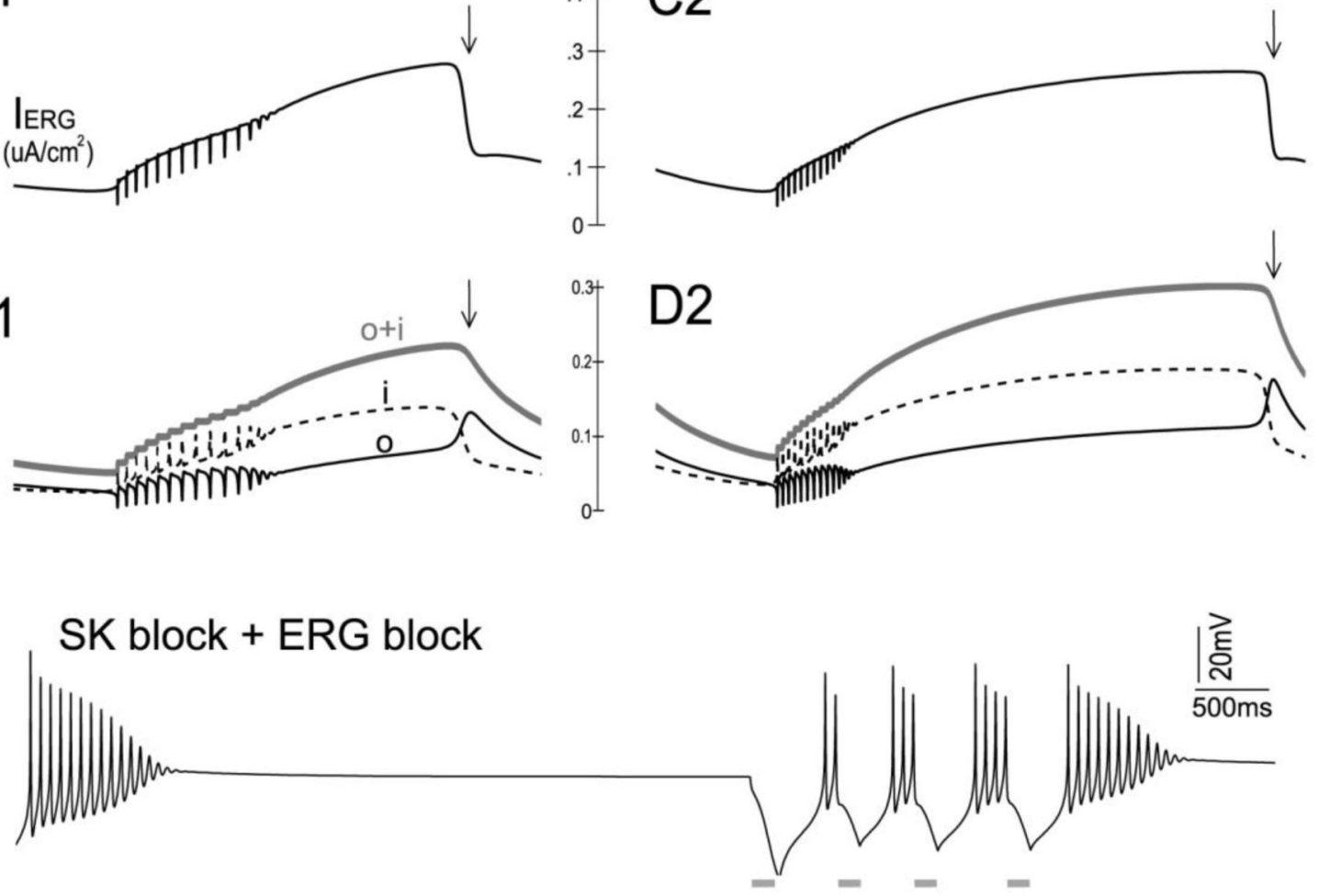

How the ERG current contributes to plateau repolarization. A1) Simulated block of the SK current produces a burst of spikes followed by DP block. A2) A 30\% reduction in the ERG conductance again shortens the burst of spikes and also prolongs the depolarized plateau. B) The time course of the L-type $\mathrm{Ca}^{2+}$ current, with the arrow indicating the regenerative decrease in this current that drives the sharp plateau repolarization in A. C) The time course of the ERG current, with the arrow showing the point at which this current tips the balance in favor of the outward currents to initiate plateau repolarization. D) The ERG channel 
fraction in the open state (o) and inactivation state (i) as well as the slow pool of $o+i$ (bold gray curve) show the slow time course of the combined pool as well as the bump in the open state during repolarization. E) A complete block of the ERG channels induces permanent depolarization block at $-40 \mathrm{mV}$. Brief ( $200 \mathrm{~ms}$ ) hyperpolarizing somatic current pulses (gray bars) temporarily relieve depolarization block 


\section{Table 1}

Comparative affinity of antipsychotic drugs for dopamine $\mathrm{D}_{2}$ receptors and $\mathrm{hERG} \mathrm{K}^{+}$channels. Adapted with permission from Shepard et al., 2007.

\begin{tabular}{llll}
\hline Drug & $\begin{array}{l}\mathbf{D}_{\mathbf{2}} \text { Receptor** } \\
\mathbf{K}_{\mathbf{i}} \mathbf{n m o l} / \mathbf{L}\end{array}$ & $\begin{array}{l}\text { hERG K+ Channel } \\
\mathbf{I C}_{\mathbf{5 0}}, \mathbf{n m o l} / \mathbf{L}\end{array}$ & $\begin{array}{l}\text { Relative Potency } \\
\mathbf{h E R G} \mathbf{I C}_{\mathbf{5 0}} / \mathbf{D}_{\mathbf{2}} \mathbf{K}_{\mathbf{i}}\end{array}$ \\
\hline Pimozide & 0.7 & $18-54.6$ & $26-78$ \\
Haloperidol & 0.7 & $26.8-1000$ & $38-1429$ \\
Sertindole & 1.2 & $2.7-14.7$ & $2-12$ \\
Chlorpromazine & 1.3 & 21600 & 16,615 \\
Risperidone & 1.7 & $148-167$ & $87-98$ \\
Thioridizine & 2.3 & $33.2-191$ & $14-83$ \\
Olanzapine & 6.4 & $231-6013$ & $36-940$ \\
Ziprasidone & 8.4 & $125-169$ & $15-20$ \\
Clozapine & 82 & $320-250$ & $4-30$ \\
Quetiapine & 155 & 5765 & 37 \\
\hline
\end{tabular}




\section{Table 2}

Time and voltage dependence of model gating variables.

\begin{tabular}{|l|l|l|l|}
\hline $\mathbf{x}$ & xhalf $(\mathbf{m V})$ & $\mathbf{x k}(\mathbf{m V})$ & time constants $: \mathbf{\tau}_{\mathbf{x}}(\mathbf{m s})$ \\
\hline$m$ & -30.0907 & 9.7264 & $\begin{array}{l}0.01+1 /(\mathrm{a}+\mathrm{b}), \\
\mathrm{a}=-(15.6504+0.4043 \mathrm{~V}) /[\exp (-19.565-0.50542 \mathrm{v})-1] \\
\mathrm{b}=3.0212 \exp (-7.4630 \mathrm{e}-3 \mathrm{v})\end{array}$ \\
\hline$h$ & -54.0289 & -10.7665 & $\begin{array}{l}0.4+1 /(\mathrm{a}+\mathrm{b}), \\
\mathrm{a}=5.0754 \times 10-4 \exp (-6.3213 \mathrm{e}-2 \mathrm{v}) \\
\mathrm{b}=9.7529 \exp (0.13442 \mathrm{v})\end{array}$ \\
\hline$h s$ & -51 & -1 & $20+580 /(1+\exp (\mathrm{v}+3))$ \\
\hline$n$ & -25 & 12 & $1+20 \exp \left(-\{\ln [1+0.05(\mathrm{v}+53)] / 0.05\}^{2} / 350\right)$ \\
\hline$l$ & -43 & 9 & $18 \exp \left[-(\mathrm{v}+60.0)^{2} / 625.0\right]+0.30$ \\
\hline$m_{H}$ & -80 & 8 & $625 \exp [0.075(\mathrm{v}+112)] /\{1+\exp [0.083(\mathrm{v}+112)]\}$ \\
\hline
\end{tabular}

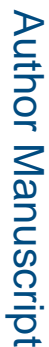

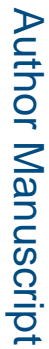

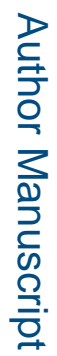

